\title{
LA TRANSFERENCIA DE CONOCIMIENTO COMO PROCESO: DE LA UNIVERSIDAD AL SECTOR EDUCATIVO. UNA MIRADA DESDE LA PEDAgOgía
}

\author{
José Manuel Touriñán López ${ }^{1}$ \\ Universidad de Santiago de Compostela
}

\section{RESUMEN}

En educación transformamos la información al conocimiento y este en educación. Cuando hacemos eso, ponemos en marcha procesos de innovación y transferencia. La transferencia es algo inherente a la educación, no solo la

$1 \quad$ Catedrático de Teoría de la Educación, Facultad de Ciencias de la Educación, Departamento de Pedagogía y Didáctica, Universidad de Santiago de Compostela

Web: http://dondestalaeducacion.com/

Researcher ID: L-1032-2014

Orcid: 0000-0002-7553-4483

Nació en 1951. Maestro de Enseñanza Primaria (1969). Licenciado (1974) y Doctor (1978) en Pedagogía con premio extrordinario en ambos casos. Catedrático de Universidad (1988). Evaluador-auditor de programas universitarios, proyectos de investigación y publicaciones científicas en organismos oficiales y revistas profesionales. Autor de más de 250 estudios (en forma de artículos de revistas de investigación y capítulos de libros especializados), de 40 libros escritos como autor único y de 10 más en coautoría. Ha recibido premios autonómicos, nacionales e internacionales. Su trayectoria profesional ha sido biografiada en repertorios europeos y americanos. Es coordinador de la red RIPEME (Red internacional de pedagogía mesoaxiológica), integrada en la Red iberoamericana de pedagogía (Redipe), y del grupo de investigación Tercera Generación (TeXe), de la Universidad de Santiago de Compostela en la que imparte docencia de Teoría de la Educación, Política de la Educación y Función Pedagógica.

Sus líneas de investigación sobre desarrollo de sistemas educativos, intervención pedagógica y función pedagógica convergen actualmente en la línea Pedagogía mesoaxiológica y construcción de ámbitos de educación: valoración del contenido de las áreas de experiencia cultural como educación y fundamentación del conocimiento necesario para la construcción ámbitos de educación, de manera que se integren en el diseño educativo valores comunes de educación y valores específicos de cada área cultural. En esta línea de investigación, y auspiciado por Redipe, desarrolla el Proyecto PIIR 004 Educere Area. Educar con las áreas culturales. 
transmisión y la difusión. Estamos obligados a preguntarnos desde la Pedagogía por la transferencia de conocimiento. Desde de la universidad transferimos conocimiento al sector educativo, por medio de procesos. EI potencial de transferencia de conocimiento que hay en el conocimiento de la educación, le otorga a la transferencia de conocimiento un lugar específico en educación. Los modelos integrados y en red, que responden a imágenes de hélice con varias palas, son una necesidad en las sociedades del conocimiento. La tercera misión de la universidad conecta innovación, empresa, sociedad civil y desarrollo cultural, social y económico bajo la perspectiva de la transferencia de conocimiento.

El lugar de la transferencia de conocimiento, en relación con la educación, no ha sido bien estudiado y tampoco bien gestionado. En este artículo se estudia la transferencia como proceso, su significado, su vinculación con la relación ciencia-tecnología-sociedad-innovación y la puesta en marcha de la evaluación de la transferencia de conocimiento para los profesores de universidad en España.

\section{PALABRAS CLAVE}

Transferencia de conocimiento; Tercera misión de la univerisdad; Innovación; Emprendimiento; Cooperación; Desarrollo tecnológico; Gestión del conocimiento.

\section{ABSTRACT}

In education we transform information into knowledge and this into education.. When we do that, we initiate processes of innovation and transfer. Transfer is inherent to education, not just transmission and dissemination. We are obliged to ask ourselves from Pedagogy about knowledge transfer. From the university we transfer knowledge to the education sector, through processes. The potential of knowledge transfer that there is in the knowledge of education, grants to the knowledge transfer a specific place in education. Integrated and network models, which respond to images of helix with several blades, are a necessity in knowledge societies. The third mission of the University connects innovation, business, civil society and cultural, social and economic development from the perspective of knowledge transfer.

The place of knowledge transfer, in relation to education, has not been well studied and neither well managed. This article studies the Knowledge transfer as a process, its meaning, its relationship with the science-technologysociety-innovation set and the implementation of the evaluation of knowledge transfer for university professors in Spain.

\section{KEY WORDS}

Knowledge transfer, Innovation; Entrepreneurship; Cooperation; University Third Mission; Technologic Development; Knowledge Management.

\section{INTRODUCCIÓN}

Herbart reclama para el educador la mirada pedagógica, bajo la idea de "círculo visual propio" que él construye desde la Pedagogía, algo que, según sus propias palabras, olvidan enteramente formarse la mayoría de los que educan antes de entregarse a ese empeño.

De lo que se trata es de elaborar un círculo visual, de tal manera que se puedan abarcar todas las consideraciones que han de ser tenidas en cuenta en cada caso. Con su ciencia el educador genera principios que le permiten decidir e interpretar desde un entramado conceptual con significado intrínseco a la educación: "Lo que debe hacer la pedagogía es deliberar sobre sus propios conceptos y cultivar una reflexión independiente. De esta forma llegaría a ser el centro de un círculo de investigaciones y no correría el peligro de ser gobernada por un 
extranjero como lejana provincia conquistada" (Herbart, 1806, p. 8. La cursiva es mía).

A día de hoy, seguimos avanzando hacia la Pedagogía como disciplina con autonomía funcional que valora como educativo cada medio que utiliza desde el conocimiento de la educación: es la perspectiva mesoaxiológica de la Pedagogía. Ese saber de perspectiva mesoaxiológica, fundamenta con el conocimiento de la educación la mirada pedagógica especializada, que es la representación mental que hace el pedagogo de su actuación; es la visión crítica de su método y de sus actos, fundada en el conocimiento de la educación. Valorar cada medio como educativo, es lo que le corresponde a la Pedagogía y por eso la Pedagogía es el saber que necesitamos para construir ámbitos de educación, es decir, para transformar en educativo cualquier medio que utilicemos (Touriñán, 2015).

En educación, desde la Pedagogía, transformamos información en conocimiento y el conocimiento, a su vez, lo transformamos en educación. $Y$ esto no es defender posturas cognitivistas, ni pensar que la educación se resuelve en conocimiento, sino insistir en que todo lo que se hace para educar exige conocimiento de aquello que educa, es decir, que valoramos como educativo lo que utilizamos para educar: transformamos el conocimiento en educación, porque no basta con conocer áreas culturales para educar, hay que ajustarlas a criterios de significado de educar y luego realizar la intervención, lo cual implica ejecutar mediante la acción lo comprendido e interpretado, expresándolo. Nada de esto se logra sin medios y el primer medio en educación es la actividad común interna y externa de las personas (Touriñán, 2014 y 2016).

En el paso de la información al conocimiento y de este a la educación ponemos en marcha procesos de innovación y transferencia. La transferencia es algo inherente a la educación, no solo la transmisión y la difusión. Estamos obligados a preguntarnos desde la Pedagogía por la transferencia de conocimiento. Vamos de la universidad al sector educativo, haciendo procesos. $Y$ entre ellos hay procesos de transferencia de conocimiento. El potencial de transferencia de conocimiento que hay en el conocimiento de la educación, le otorga a la transferencia de conocimiento un lugar específico en educación; un lugar que, dicho sea de paso, no ha sido bien estudiado y tampoco bien gestionado. De ahí mi interés en este tema para este artículo.

Y dicho esto me gustaría aclarar que en el uso normal del lenguaje se dice transferencia 'de' tecnología, transferencia 'de' resultados y sin embargo hay una cierta tendencia a decir transferencia 'del' conocimiento. Lo cierto es que hay más conocimiento del que se transfiere y, por tanto, yo usaré la preposición y no la contracción, porque realmente se transfiere algún conocimiento, no "el" conocimiento.

En este trabajo voy a abordar el significado de la transferencia de conocimiento como proceso y ello implica plantear con detalle los modelos de transferencia y asumir la relación ente ciencia, tecnología y sociedad, así como las implicaciones que se derivan para las misiones de la universidad en las sociedades del conocimiento.

Por último, dado que se acaba de publicar en España la Resolución por la que se convoca por vez primera la evaluación de la transferencia de conocimiento de los profesores de universidad, haré una revisión del contenido de la legislación, aplicando el conocimiento fundamentado en este trabajo respecto de la transferencia de conocimiento.

\section{LA TRANSFERENCIA COMO PROCESO. APROXIMACIÓN AL SIGNIFICADO}

Sin pretensión de exhaustividad hemos de 
decir que la acción es sólo un aspecto de la realidad. Entre otras cosas, en la realidad nos encontramos con estados, es decir, las propiedades, relaciones y situaciones en que una cosa o sistema está en un momento dado. Asimismo, nos encontramos con sucesos, acontecimientos $o$ eventos que son cambios de estado en los que se da un estado inicial (que puede ser el final de otro acontecimiento) y un estado final (que puede ser el estado inicial de otro acontecimiento). Pero, además, ponemos en marcha procesos, que pueden ser definidos como la transición de un estado a otro, y también ejecutamos-realizamos acciones.

Esta distinción es importante para saber de qué se habla en cada caso. Sin embargo, la distinción no es tan tajante como en principio pudiera parecer. Desde el momento en que en todo suceso se da un cambio de estado, en todo suceso hay algún proceso $\mathrm{y}$, del mismo modo, en la medida en que hay en los procesos cambios de estados, aquéllos pueden ser considerados como sucesos.

Ala vista de estas consideraciones se comprende que algunos autores nos digan que el suceso no es sólo un cambio de estado, sino también el paso de un estado a un proceso, o de un proceso a un estado, o una transformación de procesos. Y por la misma razón, nos dicen que suceso es todo lo que tiene lugar o le acaece a un sujeto o cosa en una ocasión. Desde este punto de vista, todo lo que pasó, o está pasando, puede verse, bien como un estado, bien como un suceso.

Ahora bien, los cambios de estado no acaecen solos. En ocasiones, se interviene en los cambios; es decir, hay un agente. Pues bien, todos los cambios producidos por intervención de un agente se conocen como acciones. En virtud de esta precisión podemos hablar, por ejemplo, de un acontecimiento o suceso: la muerte de César, y de una acción: la de Bruto, que produjo la muerte a César.
Por consiguiente, cuando hablamos del cambio de estado que tiene lugar o acaece a un sujeto o cosa en una ocasión, hablamos de sucesos, eventos $O$ acontecimientos, $y$, cuando hablamos del cambio de estado que un sujeto hace que tenga lugar o acaezca, hablamos de acciones.

Si sólo hay acontecimientos, o existen, además, acciones, es el problema fundamental de la explicación de la acción. En nuestra opinión, hablar de acciones no quiere decir en absoluto que no existan causas. El error básico en la disputa causa-acción estriba en no comprender que, el hecho de describir en términos de relación causal los procesos físico-químicos que tienen lugar en una acción voluntaria, no anula la necesidad de reconocer que en la acción voluntaria todos esos procesos son asumidos en un proyecto decidido por el agente, porque tiene una buena razón para conseguir el resultado que se obtiene, poniendo en marcha determinados procesos causales (Touriñán, 2016).

La explicación de la acción exige necesariamente reconocer que, en las acciones, el principio del movimiento en los procesos que desencadenan cambios de estado está en el mismo que las ejecuta. Es agente actor y agente autor de sus obras, aunque exista un foco de estimulación externa que desencadena los acontecimientos.

\section{En la transferencia de conocimiento hay} agentes, hay acciones $y$ hay procesos. La transferencia de conocimiento tiene que entenderse necesariamente como un asunto de acciones y no sólo como un asunto de acontecimientos. $Y$ la prueba más fehaciente de esto es que todos los modelos hablan de la importancia que tiene el receptory la constatación de la demanda para que la transferencia tenga éxito. Justo Nieto describe a la innovación como transformación del conocimiento en algún tipo de valor y mantiene que la innovación usa todo el conocimiento posible, no solo el tecnológico; y precisamente por eso considera que el trinomio 
I+D+i (investigación, desarrollo, innovación) no es ajustado para describir el proceso real, porque una parte del conocimiento obtenido por I + D, debe ser sumado a otro conocimiento existente y a la necesidad social nuevo productos, proceso u organización para generar Innovación. Así las cosas, para Nieto, sólo una parte del producto es lo que produce el éxito empresarial que depende del consumidor casi en su totalidad (Nieto, 2008).

La transferencia se entiende en el Diccionario como acción y efecto de transferir un paquete o producto, es el caso de la transferencia bancaria. Pero en relación con el conocimiento, cuando hablamos de transferencia no nos referimos simplemente a la transferencia de un paquete de información, vamos más allá del simple hecho de trasladar.

Tampoco se trata de integrar en la transferencia de conocimiento el significado psicológico de transferencia como desplazar afectos y emociones experimentados por un individuo hacia una persona distinta de la aquella que originó los afectos. Por supuesto, algo de eso hay cuando se consigue que el receptor del producto adquiera sentimientos favorables hacia lo transferido (motivación de compra), pero la demanda no se resume en las motivaciones del productor o creador del conocimiento a transferir, ni es igual a la del que hace la transferencia. Transferir no es solo transferir afectos o transferir lo propio de un concepto a otro.

En Psicología, el transfer va más allá de los afectos y entiende la transferencia como posibilidad de que el receptor utilice lo transferido para actividades y procesos distintos de los que ha usado el creador. En relación con el aprendizaje se habla siempre de (Úbeda, 2013):

- Transferencia positiva: Es la que se produce cuando una tarea mejora el rendimiento sobre otra tarea distinta. Por ejemplo, está demostrado que el entrenamiento de fuerza máxima o los ejercicios de squat jump con ligeras sobrecargas tienen un efecto positivo sobre el rendimiento en el sprint.

- Transferencia negativa: Cuando la realización de un ejercicio dificulta o empeora la realización del siguiente. Si pusiéramos a Usain Bolt a rodar $2 \mathrm{~h}$ diarias en bici probablemente el efecto que tuviese sobre su velocidad sería más bien nefasto.

- Transferencia neutra: Una tarea no tiene efecto sobre la otra. Evidentemente, ni mejora, ni empeora, porque no tienen absolutamente nada que ver.

En Didáctica, la transferencia de aprendizaje está muy sistematizada y se han determinado seis niveles, agrupados en cuatro y dos respectivamente según sean transferencias intra o inter y transcontextual (Haskel, 2001, pp. 29-30):

\section{Transferencia intracontextual:}

- Transferencia no específica (Lo que se aprende se conecta con el conocimiento previo)

- Transferencia de aplicación (Se aplica lo que se aprende en el mismo contexto)

- Transferencia de contexto (Se aplica lo que se aprende en un contexto no muy diferente)

- Transferencia próxima (Se transfiere conocimiento previo a situaciones similares, pero no idénticas).

\section{Transferencia intercontextual o}

transcontextual:

- Transferencia lejana (Se transfiere conocimiento previo a situaciones $\mathrm{o}$ contextos muy diferentes)

- Transferencia creativa (La transferencia va más allá de la analogía simple y se crean -o 
utilizan- nuevos conceptos).

En todos estos casos hablamos de transferir algo a uno mismo o a otro sujeto, pero haciendo referencia al proceso mental que genera nueva comprensión, no al sentido propio de la transferencia de conocimiento desde la universidad a la sociedad. Hay más modos de ver la transferencia en el proceso instructivo, pero explicar procesos mentales no es explicar el proceso de transferencia de conocimiento de la universidad a la sociedad (Gagné, 1971; Haskell, 2001; Gómez, Sanjosé y Solaz, 2012).

En la transferencia, siempre hay agentes actores y autores, hay procesos $y$ hay especificidad en el concepto. $Y$ la transferencia de conocimiento debe afrontar la manera de ver en qué medida las buenas prácticas de transferencia de aprendizaje pueden dar lugar a figuras o actividades evaluables en los criterios de transferencia de conocimiento. Por ahora, nada del trabajo que se ha hecho de ajustar criterios para evaluar transferencia de conocimiento en educación se ha hecho de manera particular, atendiendo específicamente a la innovación educativa y todo parece indicar que cada profesor tendrá que romperse la cabeza y aguzar su ingenio para ver cuánto de lo que él hace que da lugar a innovación educativa y transferencia de conocimiento se ajusta a los criterios de la convocatoria para que sea "administrativamente" considerado transferencia que genera innovación en el centro escolar y en la sociedad o en las ciudades que son educadoras (Díaz, 2010).

Por su parte, la Universidad Autónoma de Barcelona, ya ha fijado en su web una diferencia asumible por ellos entre transferencia de conocimiento y transmisión de conocimiento. La transferencia de conocimiento (TC) es el conjunto de actividades dirigidas a la difusión de conocimientos, experiencia y habilidades con el fin de facilitar el uso, la aplicación y la explotación del conocimiento y las capacidades en I+D de la universidad fuera del ámbito académico, ya sea por otras instituciones de $I+D$, el sector productivo o la sociedad en general.

Para la UAB, el concepto de 'transferencia de conocimiento' es diferente del de 'transmisión de conocimiento', puesto que mientras que en el caso de la transferencia se persigue incorporar el conocimiento a una cadena de valor para que genere un retorno económico, en el caso de la transmisión solo se busca la publicación, la divulgación o la docencia (conocimiento extraído el 10 de febrero de 2019 de la página web de la UAB) https://www. uab.cat/web/investigar/itinerarios/innovaciontransferencia-y-empresa/transferencia-delconocimiento-1345667266489.html.

Para esa Universidad hay dos Conceptos clave en la transferencia de conocimiento que van más allá de la transmisión y que distinguen y cualifican a la transferencia de conocimiento:

- Innovación abierta (open innovation), que designa el modelo de innovación que se desarrolla principalmente a partir de la aparición de fondos públicos destinados a la investigación colaborativa público-privada, donde universidad y empresa comparten objetivos, recursos y los derechos de propiedad intelectual registrada (RPI).

- Investigación colaborativa que es el canal de transferencia importante de conocimiento entre la academia y la industria, el gobierno y las empresas, en ambas direcciones, y puede conducir a otras actividades de transferencia de conocimiento, tales como las licencias o la formación de spin-off.

La transferencia de conocimiento se presenta, por tanto, como una estipulación no inventiva del término 'transferencia', pues se le atribuye un uso nuevo a un término que ya tenía otros usos, tal como ya hemos visto (Scheffler, 1970).

Con todo, debe aclararse que la diferencia 
entre la transferencia y la transmisión no queda bien delimitada, porque en la transferencia hay actividades de difusión del conocimiento que tienen que ver con guías didácticas, artículos de prensa, jornadas de puertas abiertas, convivencias tecnológicas y libros de buenas prácticas que son actividades reconocidas en el ámbito de la transferencia de conocimiento. Existe la transferencia por difusión del conocimiento y es una de las formas más extendidas de transferencia entre los profesores de universidad que desempeñan ordinariamente tareas de docencia, investigación, representación y gestión.

Acaso la diferencia más grande entre transmisión y transferencia estriba en que la transmisión solo se delimita por la actividad y el medio utilizado, no por la finalidad. En la transmisión es el medio el que marca la comunicación de lo que se transmite, así se transmite un virus y se transmite una noticia por radio que emite en frecuencia modulada. En la transferencia de conocimiento lo que prima es la finalidad y el uso que se espera que se haga con lo transferido que, a veces, da lugar a una licencia de uso, otras, a una venta de patente $y$, otras, a un contrato de prestación de servicios. Pensemos sino en la cantidad de transferencia de conocimiento que se da en un contrato de prestación de servicios de asesoría a una ONG, o en la puesta en práctica de una buena práctica de la conocida figura educativa de aprendizaje-servicio.

Para mí, es un hecho que transferencia de conocimiento y transmisión de conocimiento son conceptos distintos, pero también es un hecho que la transmisión puede tener valor de transferencia de conocimiento y que hay actividades de difusión que son transmisión y son transferencia a al vez. Pretender negar esa relación y diferencia entre ambos conceptos, es negarle la extensión que le corresponde al término la transferencia y menospreciar el valor de la difusión y la transmisión en sí misma y en relación con la transferencia (Conesa, 2019).

La enseñanza, la publicación y la divulgación son eficaces para transferir conocimiento, para el logro de avances en una disciplina y para conseguir mejoras en la calidad de vida. Ahora bien, en la práctica y en una economía basada en la transferencia, se hacen necesarios nuevos métodos y procesos de transferencia que van dirigidos desde las instituciones de educación superior hacia la sociedad y al tejido empresarial, con el objetivo de atender de forma específica y ajustada a las peculiaridades de las diferentes áreas de conocimiento. No es igual el conocimiento transferible, ni son los mismos problemas los que plantea la transferencia en áreas de ingeniería que en ciencia sociales y humanas y en educación. Hablar de la transferencia de conocimiento como actividad, no tiene que impedir el reconocimiento de que, actualmente, en todas las áreas de conocimiento y en cada facultad, la transferencia de conocimiento ha alcanzado un grado tan elevado de especialización, dada su caracterización como transferencia en red que vincula agentes, elementos del proceso y factores influyentes en el proceso, que no puede ser planteada la transferencia como una actividad inespecífica en cualquier caso, ni como una función ordinaria más del profesor, si no se desarrolla antes la competencia para gestionar el proceso de transferencia de conocimiento (Molero, 2008; Castro, Fernández, Pérez y Criado, 2008; Martínez, 2017; Bayona y González, 2010; Martínez-Gómez, 2017).

En el imaginario colectivo de los profesores de universidad, los profesores crean el conocimiento que va a ser transferido por los agentes de la transferencia. $Y$ el proceso de la transferencia implica, además del conocimiento creado (el objeto a transferir), la obtención del conocimiento especializado y específico del proceso de transferencia que es propio de los mediadores de la transferencia desde las 
oficinas de transferencia y desde los centros de creación de conocimiento. Eso no impide reconocer, al mismo tiempo, que algunas de las actividades más comunes utilizadas como transferencia son realizadas por los profesores de universidad, por ejemplo: la traducción del conocimiento, la transferencia de conocimientos, el intercambio de conocimientos, las prácticas de ese conocimiento creado, utilización de la investigación, la visualización de sus aplicaciones, la divulgación, la diseminación y la difusión del conocimiento creado. Pero de ahí a convenir que la transferencia es una función más de los profesores de universidad, hay un camino muy largo y un complejo proceso que afecta a intereses, derechos y desarrollo de competencias de los profesores que no se resuelven sin coste, ni sin cambios en la organización de los recursos humanos de la universidad. Por descontado que, a pesar de lo dicho, la Administración puede actuar como si eso ya fuera un hecho y el camino ya estuviera recorrido (Graham, Logan y Harrison, 2006).

Lo ideal sería que los contratos de investigación, la investigación colaborativa, la afluencia de estudiantes a eventos de puertas abiertas y de oferta tecnológica y de conocimiento y las actividades de transferencia organizadas por las oficinas universitarias de transferencia de tecnología, sean formas particularmente importantes de transferencia de conocimientos relacionadas con los investigadores en particular, o al menos con los centros y carreras de oferta de servicios sociales y culturales y no solo un reflejo de lo que necesitan para transferir conocimiento las carreras tecnológicas, que, por definición, están vinculadas a las tecnologías de producción (Bekkers y Bodas, 2008). La realidad de los hechos es que la fluencia del conocimiento entre la academia y la industria varía de acuerdo a la disciplina y que la transferencia de formación, de resultados de investigación y de tecnologías no es igual en cualquier caso, ni requiere siempre la misma especialización (Martínez-Gomez, 2017; Bayona y González, 2010; Medina, 2016).

Para Bayona y González (2010), las actividades de transferencia de conocimiento que se presentan en las universidades son las siguientes (Cuadro 1): 


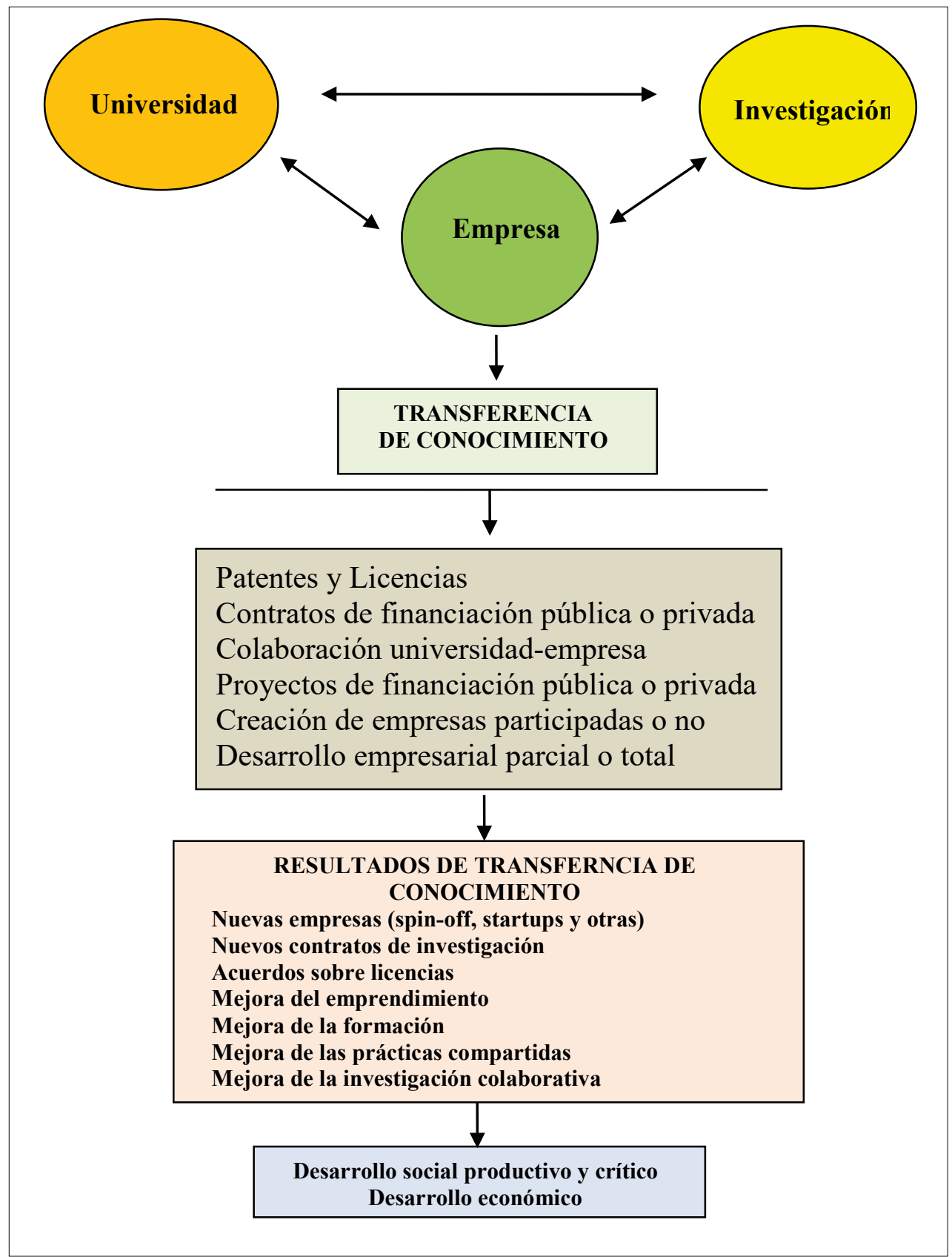

Cuadro 1: Actividades de Transferencia de conocimiento

Fuente: Bayona y González, 2010. Elaboración propia.

Para Vilalta, la función de desarrollo económico y social productivo y crítico desde la universidad podría definirse a partir de la presencia, más o menos intensa, de las siguientes ocho subfunciones (Vilalta, 2013; ACUP, 2008; ):
- Capital humano e inserción laboral de los graduados y doctores. Incorporación de los graduados y doctores al tejido social, económico y laboral. 
- Propiedad intelectual. Transferencia de conocimientos y de tecnología protegida previamente mediante la gestión de la propiedad industrial.

- Nuevos proyectos empresariales y fomento del espíritu empresarial. Fomento del tejido empresarial a partir de la creación de empresas spin-off basadas en los resultados de la investigación de los grupos académicos.

- Contratos y asesoramiento técnico a empresas. Realización de contratos con empresas e industrias en ámbitos de investigación y desarrollo tecnológico.

- Contratos y asesoramiento con instituciones públicas. Realización de acuerdos, convenios y contratos con instituciones públicas o entidades sin ánimo de lucro en materias de interés público.

- Diseño, desarrollo y evaluación de políticas públicas. Participación y asesoramiento técnico del personal de la universidad en el análisis de problemáticas sociales y en el diseño, implementación y evaluación de políticas públicas de los diferentes niveles gubernamentales.

- Fomento de la vida cultural y social. Participación en actividades o proyectos culturales o sociales, aportando la experiencia y las capacidades de las universidades y los grupos de investigación de estas.

- Comunicación y divulgación científica. Fomento de la comprensión pública de la ciencia. Interacción con la sociedad y comunicación y divulgación científica y cultural.

Por su parte Rosli y Rossi (2014), plantean los siguientes tipos de actividades de transferencia de conocimiento (Cuadro 2):

Cuadro 2: Modelos de transferencia de conocimiento en universidades

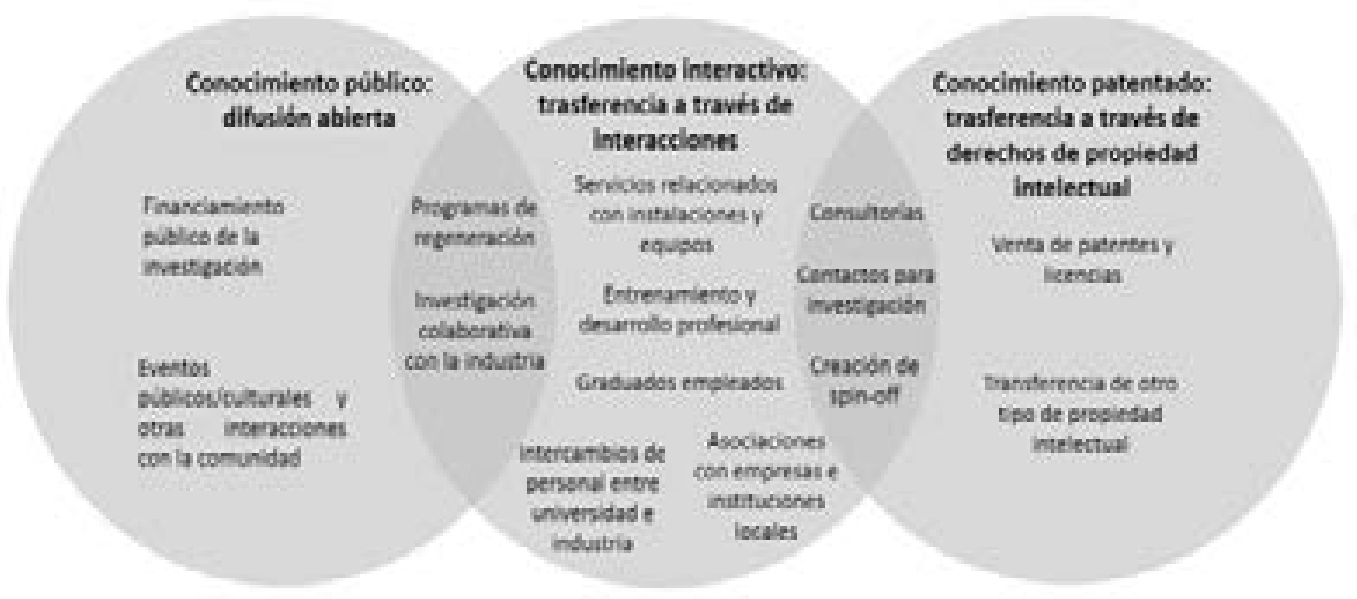

Fuente: Martínez-Gómez, adaptado de Rosli y

Rossi (2014). 
Lo que resulta indudable es que el beneficio del capital humano está siendo asumido como una realidad que hace necesaria la transferencia de conocimiento, con independencia de las motivaciones particulares de cada investigador; es una necesidad institucional y social con valor productivo y de servicio (Cuadro 3).

Cuadro 3: Modelo beneficio de Capital Intelectual

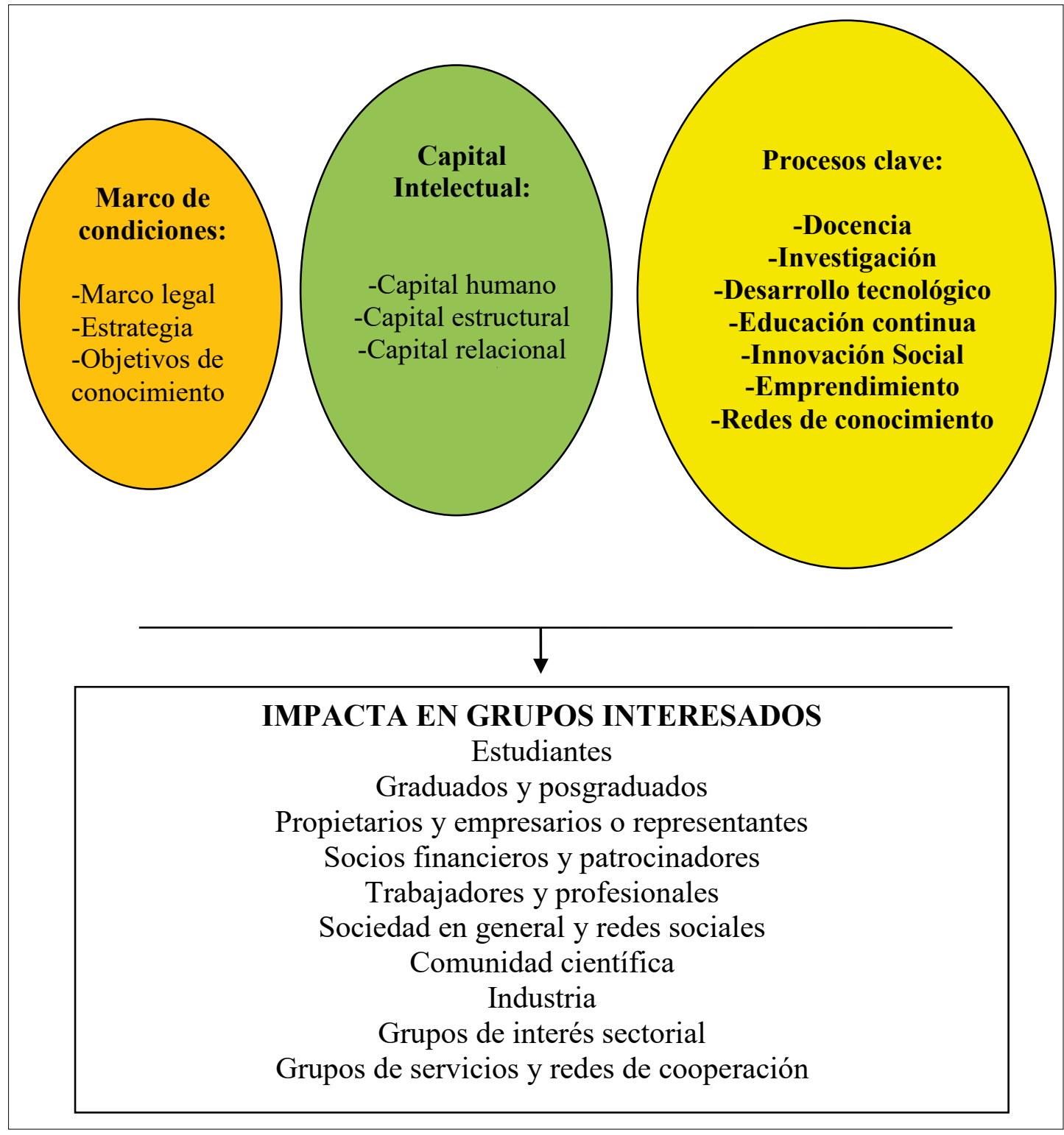

Fuente: FH JOANNEUM, 2010, p.

51. Elaboración propia. 
Desde la perspectiva del protagonismo de la Universidad, la CRUE mantiene que, en la transferencia de conocimiento, se relacionan e interactúan los siguientes agentes (CRUE, 2018):

- Centros tecnológicos, regulados por el Real Decreto 2093/2008, de 19 de diciembre, centros tecnológicos (CT) y centros de apoyo a la innovación tecnológica (CAIT) de ámbito estatal

- Parques científicos y tecnológicos, así como la Asociación de Parques Científicos y Tecnológicos de España (APTE)

- Empresas (en particular, spin-offs y startups)

- Organismos de intermediación («Interfaces»). De carácter público o privado, que funcionan como conectores con las empresas, al apoyar el desarrollo de servicios intensivos de conocimiento con el objetivo de aumentar su productividad, margen de beneficios o mejorar, en definitiva, la coordinación y la capacitación o cualificación y movilidad de su personal (OTRIs, OTTs, OPIs, etc.)

- Organismos para el fomento de la empleabilidad. De carácter público o privado, son organismos y organizaciones que se enfocan en la cultura del emprendimiento, en la formación complementaria para mejorar el acceso al empleo, o en el mentoring para la creación de start-ups, y para su conexión con los clubes de inversores.

Las universidades son los principales productores de conocimiento científico, tecnológico, social y humanístico. No obstante, en todos los procesos de transmisión de conocimiento universitario (incluyendo la Transferencia de tecnología y la de conocimiento) conviven diversidad de agentes y factores condicionantes. De ahí que en los modelos de transferencia se hable de modelo en red y se aplique el principio de bidireccionalidad; se va en ambas direcciones. Este hecho se caracteriza porque los flujos de información que determinan la naturaleza y el tipo de interacción entre los agentes en la estructura van a modificar las características del conocimiento generado, debido a la propia retroalimentación del sistema y como consecuencia directa de dichas interacciones (CRUE, 2018).

El modelo Bozeman (2000) resume los factores y agentes que intervienen en el proceso de transferencia (Bozeman, 2000; Bayona y González, 2010; Martínez-Gómez, 2017):

- El objeto a transferir (conocimiento científico, tecnologías "físicas", métodos, procesos, know-how, etcétera).

- Los productores de conocimiento y sus características (el investigador o grupo de investigación y su institución).

- Las características de los medios de transferencia. Vehículos formales 0 informales, a través de los cuales se transfiere la tecnología/conocimiento (licencia de patentes $u$ otros títulos de propiedad industrial e intelectual, programas de investigación en colaboración, documentos, interacción personal, spinoffs, contratos o convenios, intercambio de personal, etc.)

- Los destinatarios o usuarios o receptores del conocimiento (empresas, ONG, agencias del gobierno, grupos de la sociedad civil, etc..). Sectores productivo y no productivo. Empresas, Administraciones Públicas y Centros Tecnológicos.

- El entorno de la demanda del conocimiento. Factores (del mercado u otros como el contexto legal e institucional) relacionados con la necesidad existente en el entorno socio-económico-cultural del objeto 
transferido (precio de la tecnología o conocimiento, posibilidad de sustitución, relación con las tecnologías/conocimientos actualmente en uso, subvenciones, etc.)

- Los Agentes dinamizadores de la transferencia:Enmiopinión, habríaqueañadir al modelo, dado el especial protagonismo que cobran entre los agentes, aquellos que son conocidos como dinamizadores de la transferencia en el lenguaje de la gestión del conocimiento. Responsables y técnicos de la Oficina de Transferencia de Resultados y del Servicio de Investigación de la universidad. En ocasiones también los propios investigadores pueden ser agentes dinamizadores además de productores de conocimiento (Cuadro 4).

Cuadro 4: Red responsable de innovación y transferencia

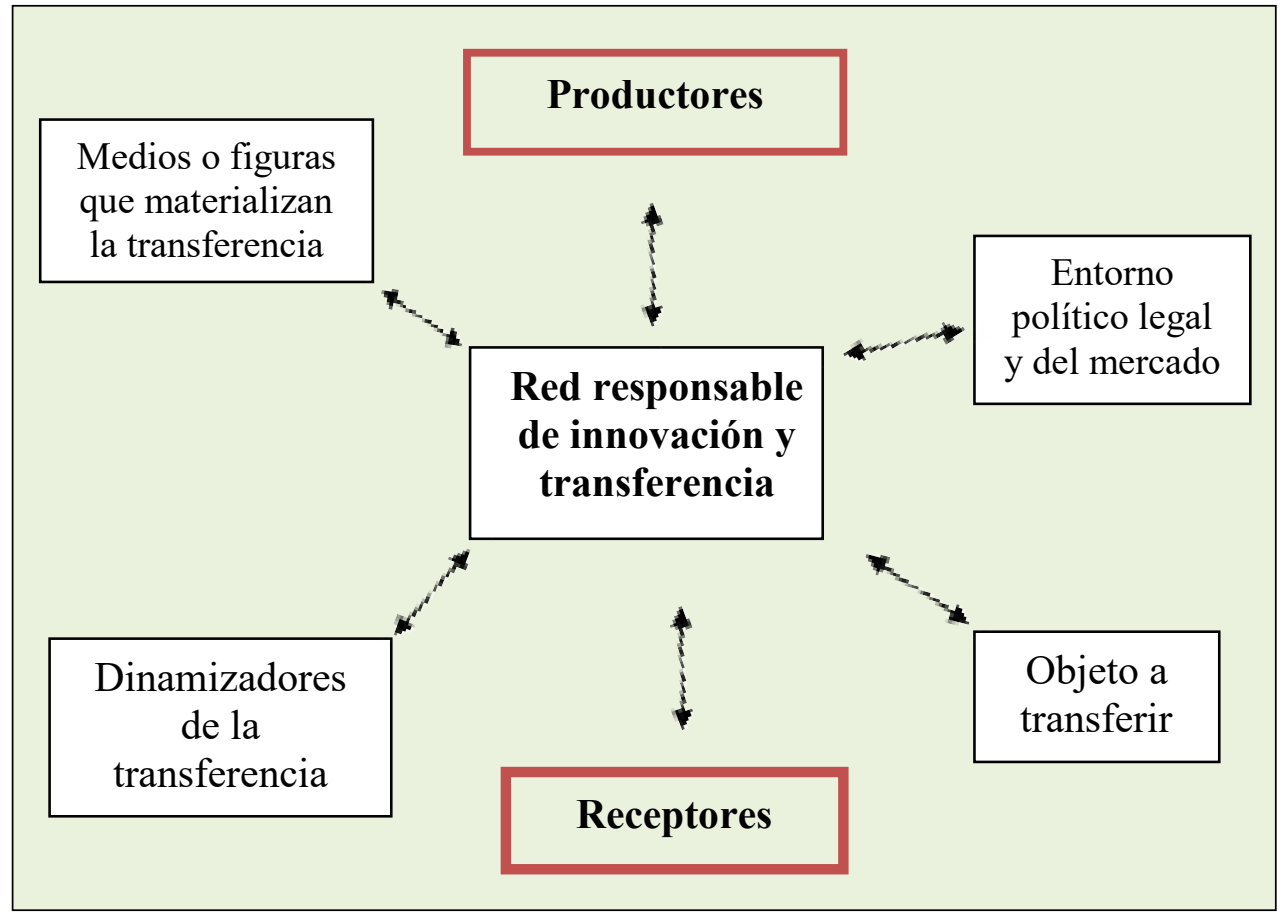

Fuente: Bozemam, 2000. Elaboración propia.

2. EL MODELO DE TRANSFERENCIA DE CONOCIMIENTO TIENE QUE ESTAR ORIENTADO EN RED A LA INNOVACIÓN PRODUCTIVA, CULTURAL Y SOCIAL

De acuerdo con Arias y Aristizábal, podemos decir que, con el advenimiento de la sociedad del conocimiento y la economía de bienestar (Bell, 1973; Drucker, 1993), la manera tradicional de producción de conocimiento científico y tecnológico de las universidades y centros de investigación, denominada Modo 1 ó Ciencia 1, ha sufrido una serie de transformaciones que han propiciado la configuración y el tránsito hacia el Modo 2 ó Ciencia 2 (Gibbons et al.1994; Gibbons, 1998; Nowotny et al., 2001)

En el Modo 1, los problemas se plantean y solucionan dando atención principalmente a unos intereses académicos de una comunidad específica; mientras que en el 2 , el conocimiento se produce a la luz de un contexto de aplicación, es decir, buscando ser útil bien sea a la sociedad, al Estado o a las empresas. Se pasa de una concepción disciplinar a una concepción transdisciplinar y el conocimiento ya no queda 
vinculado solo a la Universidad encerrada en sí misma. La universidad, cada vez más, busca la función de servicio, no solo al conocimiento, sino también al desarrollo económico, cultural y social productivo y crítico.

La mirada dirigida desde la universidad hacia el desarrollo económico productivo hace que la transferencia de conocimiento pueda ser considerada, a su vez, de acuerdo con esos dos modos de producir conocimiento científico y tecnológico, de tres modos: no comercial, comercial y de creación de nuevas empresas (Upstill y Symington, 2002; Pirnay, Surlemont y Nlemvo, 2003; Bueno, 2007):

- El Modo 1 (no comercial) se refiere, básicamente, a la difusión del conocimiento sin ningún tipo de interés comercial $y$ contratos entre los emisores y receptores; se lleva a cabo en escenarios académicos mediante publicaciones, seminarios, ponencias, diplomados, cursos de extensión;

- El Modo 2 (comercial), la transferencia parte de un acuerdo comercial entre la universidad y su contraparte, bien sea el Estado o la industria, y se realiza por medio de consultorías, capacitaciones, investigación conjunta y comercialización de licencias o patentes de productos desarrollados durante la investigación;

- El Modo 3 (creación de nuevas empresas) implica la creación de las Spin-off universitarias, empresas dedicadas a la explotación del conocimiento, tecnología o resultados de investigación desarrollados dentro de las universidades.

En esta misma línea se expresan diversos autores, apuntando al sentir general y común de que la transferencia, se haga mediante el mecanismo de divulgación y difusión o se haga orientada a resolver problemas sociales, responde básicamente a tres grandes modelos (Hidalgo, León y Pavón, 2002: Arias y Aristizábal, 2011; Velasco, Zamanillo y Intxaurburu, 2007):

- Modelo lineal, en el cual la transferencia está precedida de los descubrimientos científicos y de la consecución de patentes. En el modelo lineal están implicados la universidad, el científico o centro de investigación, la oficina de transferencia de resultados de investigación (OTRI) y las empresas.

- Modelo dinámico, que mejora el modelo lineal y tiene como propósito la transferencia de conocimiento por medio de la comercialización o difusión

- Modelo integrado, que ha evolucionado, desde el protagonismo del Estado en las relaciones entre las empresas y el Estado, a una interacción entre el Estado, la empresa y la universidad con campos de acción delimitados para cada uno; para llegar a su versión última, en la que cada uno de los actores asume las funciones propias y las de todos, de tal manera que las universidades crean empresas y éstas, a su vez, crean centros de investigación.

También hay una coincidencia generalizada respecto al hecho de que la transferencia de conocimiento no es lineal; es, preferentemente, en redes, cuyo flujo vital es el conocimiento creado y transferido. Diferentes agentes $\mathrm{y}$ organizaciones intercambian información y conocimiento para producir innovaciones en el marco de relaciones de cooperación y redes a nivel territorial local, regional, nacional o internacional.

Por consiguiente, el contenido básico del modelo integrado quedaba establecido al considerar a la universidad como co-protagonista del desarrollo productivo en una imagen de hélice de triple aspa (mal Ilamado modelo de 'triple hélice', por 
una mala traducción del texto inglés, que dice expresamente "hélice triple": administración, universidad y empresa (Etkowitz, Leydesdorff, 1997). Al modelo de Hélice triple le corresponden fundamentalmente tres objetivos:

- Dirigir el proceso de transferencia de conocimiento tecnocientífico hacia la generación de innovación.

- Promover la creación de la cultura científica y de innovación que necesita la sociedad actual.

- Formar a los asesores y gestores tecnocientíficos o en I+D como agentes inductores de innovación (Cuadro 5).

Cuadro 5: Transferencia de conocimiento hélice triple

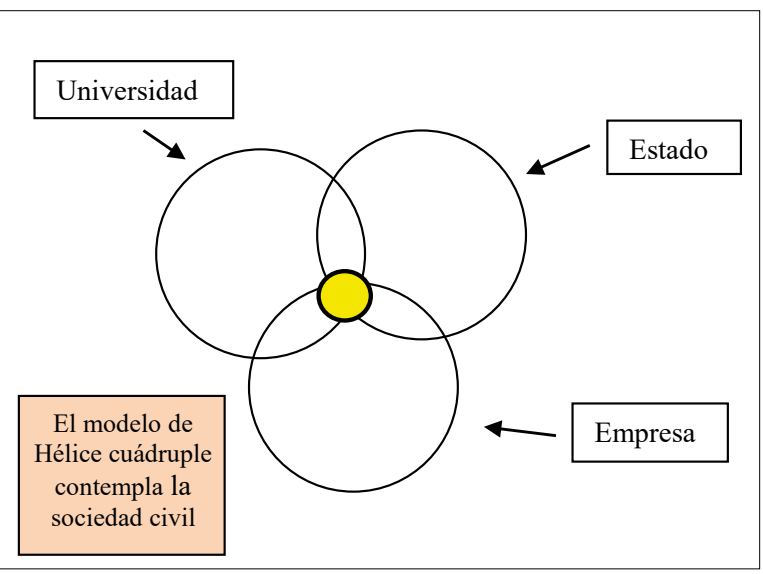

Fuente: Touriñán, 2016. Adaptado de Etzkowitz y Leydesdorff, 1997

En cualquier caso, después de años de aplicación del modelo integrado de Hélice de tres aspas, parece poder afirmarse que este, si bien explica una buena parte de mecanismos de relación entre universidad y empresa e investigación, no es un buen ejemplo para convertirse en modelo social, porque no se conjuga bien con el papel de la sociedad civil y las innovaciones derivadas de realidades culturales y educativas que forman parte de la sociedad y que también contribuyen al desarrollo, igual que la empresa, la universidad y la administración pública.

Según Teresa González, puede afirmarse, con fundamento en investigación, que el modelo de hélice de triple aspa (González, 2009):

- Selecciona sólo una pequeña parte del panorama total de la investigación;

- Estiliza las condiciones y los sucesos reales para producir una imagen de un espacio de agencia abstracto (intersticial);

- Exagera la comunalidad y el consenso entre los distintos actores y partes implicadas, al tiempo que atenúa la diferenciación y el conflicto de intereses que surge de la especificidad sistémica de las partes intervinientes.

Desde finales de la primera década de este milenio, se ha incorporado a la literatura especializada el modelo en red de hélice cuádruple (de cuatro aspas), que agrega un cuarto componente al marco de interacciones entre la universidad, la industria y el gobierno: la sociedad civil y los medios de comunicación de masas de la sociedad digital. El objetivo es cerrar las brechas entre la innovación y la sociedad civil. De hecho, este marco afirma que bajo el modelo de hélice de triple aspa, las tecnologías emergentes no siempre coinciden con las demandas y necesidades de la sociedad, lo que limita su impacto potencial. Este nuevo marco tetrádico enfatiza la responsabilidad social de las universidades, además de su papel de docencia e investigación. El modelo en red de cuádruple aspa es el es que la Unión Europea se propone adoptar para el desarrollo de una sociedad competitiva basada en el conocimiento (Carayannis y Campbell, 2009 y 2010). El paso de una lógica tríadica a una lógica tetrádica, que involucra a universidad, empresa, administración pública y comunidadsociedad civil, en un mundo digital y globalizado, parece indicar que la universidad refuerza su 
papel de motor del desarrollo tecnológico y de responsabilidad en el desarrollo económico, social y cultural, productivo y crítico: además de docencia e investigación, hay una tercera misión de la universidad que la define como motor del desarrollo tecnológico y una cuarta misión que la orienta al desarrollo social productivo y crítico, desdoblando la misión clásica de desarrollo social y cultural productivo y crítico, cuya pujanza está relegando a otro plano las misiones clásicas de estudio y profesión (CRUE, 2018; Bueno, 2007; Vilalta, 2013). Además de la docencia, el estudio, la investigación y la profesión, esta nueva prioridad caracteriza a la universidad en la innovación, el emprendimiento y la cooperación social (Touriñán, 2016):

- La universidad tiene un papel fundamental para propiciar y generar innovación en el Sistema de I+D+I, actuando como agente y espacio dinamizador de estos procesos de innovación.

- La Universidad, tiene un papel fundamental como agente de emprendimiento, a través de la puesta en práctica de procesos de transferencia de conocimiento.

- La universidad tiene una función de compromiso con el crecimiento y el desarrollo sostenible de la comunidad social en la que se integra y es facilitadora de una mayor cooperación social en los procesos de $1+D+I$ en la sociedad y economía del conocimiento.

Atendiendoaladefinición recogidaporlaComisión Europea en el 'Libro Verde de la Innovación', la innovación es la transformación de una idea en un producto o un servicio comercializable nuevo o mejorado, un procedimiento de fabricación o distribución operativo, nuevo o mejorado, o un nuevo método de proporcionar un servicio social. Es por lo tanto, por definición, una tarea, un resultado y un proceso. A veces mejoramos los equipos o las funciones de los equipos que intervienen en la innovación (innovación de organización). A veces, la innovación se refiere a cambios en el objeto producido (innovaciones de productos). A veces, se mejora el proceso de producción de bienes o de prestación de servicios (innovaciones de proceso) (Comisión Europea, 1995).

A pesar de la existencia de numerosos modelos que han tratado de explicar lo que constituye el proceso de innovación, la mayoría de ellos resultan incapaces de capturar toda la complejidad de la realidad que trata de describir. A medida que se han producido avances en el entendimiento del proceso de innovación, han ido surgiendo nuevos modelos cada vez más sofisticados. En la actualidad, los modelos coexisten en sus diferentes formas (Velasco, Zamanillo y Intxaurburu, 2007; Padmore, Schuetze y Gibson, 1998).

La Comisión Europea estableció la existencia de diversos modelos de innovación (Comisión Europea, 1995, 2004 y 2011):

- Innovación derivada de la ciencia (de su empuje, Technology Push)

- Innovación derivada de las necesidades del mercado (Market Pull)

- Innovación derivada de los vínculos entre los actores en los mercados

- Innovación derivada de redes tecnológicas

- Innovación derivada de redes sociales.

Lo que persiguen los modelos es que, por medio de la transferencia de conocimiento, la innovación llegue a la empresa y a la sociedad. Hay innovación de proceso, de producto y de organización y para todo ello se puede transferir conocimiento (Fernández, 2000). La innovación no es un simple cambio, la innovación exige referencia a necesidades sociales, culturales o empresariales para las cuales el cambio 
implícito en la innovación supone una mejora o satisfacción de la necesidad y puede basarse en una nueva tecnología, como es el caso de la innovación vinculada a las TICs y puede incluso conllevar un cambio de mentalidad. Si esto es así, la transferencia de conocimiento debe atender prioritariamente a los desarrollos productivos, sean sociales, culturales o económicos, pues, en términos de emprendimiento y transferencia es tan importante pensar en una empresa al uso como pensar en una ciudad educadora, en una ciudad creativa o en una ciudad amigable con los mayores, que son áreas de interés de la educación y, por consiguiente, de la Pedagogía (Touriñán, 2017; SI(e)TE, 2012; Claxton, 2001; Sebastián, 2008; Herrera, Bonilla y Molina, 2013; https://es.unesco.org/creative-cities/content/ ciudades-creativas; Asociación Internacional de Ciudades Educadoras; OMS, 2007, https://www. who.int/ageing/age friendly cities guide/es/).
Finalmente hay que defender que la innovación tiene lugar en la empresa, pero el conocimiento en la que se sustenta puede provenir de muy diversas fuentes: interna a la empresa (inhouse); proveedores; las empresas iguales (peers) (competidoras o no); clientes10 y sector público (transfiere conocimiento a través de institutos técnicos o laboratorios de investigación, la celebración de diversos eventos como conferencias, a través de agencias reguladoras, etcétera.

El Modelo integrado, insiste en la importancia del aprendizaje que tiene lugar dentro y entre las empresas, y sugiere que la innovación es, fundamentalmente y de manera genérica, un proceso distribuido en red en el que la sociedad civil tiene su lugar (Cuadro 6).

Cuadro 6: Modelo en red para gestión de innovación

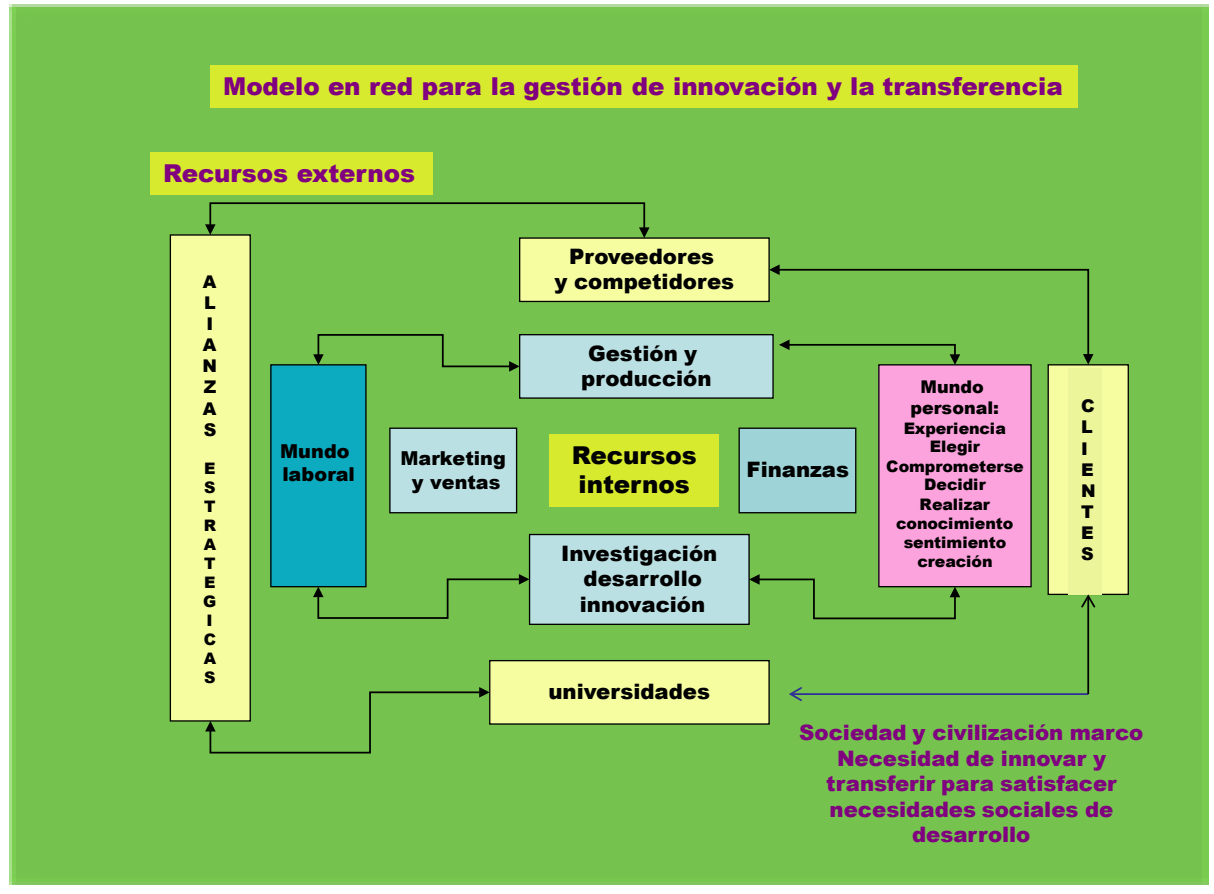

Fuente: Trott, 1998. Elaboración propia. 
El modelo en red permite entender que el incremento de conocimiento se consigue fundamentalmente mediante la ejecución de actividades de I+D, pero eso no impide entender que hay otras modalidades de aprendizaje como son el aprendizaje por la práctica ("learning by doing"), que se logra con la realización de las actividades de producción; el aprendizaje por el uso ("learning by using"), que se extrae de estudiar la forma en que los clientes emplean los productos de la empresa; el aprendizaje por el error ("learnig by failing"), proveniente del análisis de las decisiones erróneas adoptadas. Estos lemas de educación se aplican en la formación continua desde el aprendizaje-servicio que es una buena mezcla de todos ellos muy útil en pedagogía laboral, pedagogía gerontológica, en pedagogía ambiental, en pedagogía social y en cooperación al desarrollo (https:// aprendizajeservicio.net/que-es-el-aps/). Este flujo de formación continua se hace de manera que los nuevos conocimientos se acumulen a los conocimientos previamente existentes y de este modo se incrementa la convicción de que las empresas que triunfarán en el futuro serán aquellas que consigan descubrir cómo lograr el compromiso de su gente y que desarrollen una capacidad de aprender a todos los niveles de la organización (Velasco, Zamanillo y Intxaurburu, 2007; Vilalta, 2013; UNESCO, 2005).

Gestionar el proceso de innovación en red supone en sí mismo un aprendizaje considerable, incluyendo el aprendizaje organizacional, y éste, no estará exento de costos, tanto en términos de tiempo, como de inversión en equipos y formación. Es un conocimiento especializado que hay que hacer si se quiere conseguir efectividad en la transferencia de conocimiento desde los centros de formación y desde cada trabajo de investigación en la universidad (MartínezGómez, 2017). Sin embargo, los beneficios potenciales a largo plazo son considerables: eficiencia y manejo de información en tiempo real a través de todo el sistema de innovación, mayor conocimiento mutuo entre los agentes, potenciación de la investigación colaborativa; difusión social del trabajo universitario; implicación productiva en la sociedad, etcétera (López, Blanco y Guerra, 2009).

En mi opinión la complejidad del proceso es tal que hay que empezar a hablar realmente de la transferencia y no solo como desiderata. y por tanto asumir que el cambio innovador se puede referir a una idea, un material, una práctica, un contenido, alguna metodología, un patrón cultural, una relación entre las personas o instancias que participan en el hecho educativo, la forma de aplicar una norma, un procedimiento administrativo, un artefacto organizacional, una técnica transferible a una empresa o centro educativo, una buena práctica o una creencia o un valor y un largo etcétera que solo se acaba con las posibilidades de la creatividad de los agentes. Ahora bien, para que el cambio surta efecto debe ser asumido e interiorizado en el plano personal, y, debe ser institucionalizado en el plano de la organización receptora; no es una tarea sencilla ni simple; es una tarea específica y especializada que responde a una necesidad social sentida. $Y$ cuando hablamos de actividad específica, con fundamento en conocimiento especializado que sirve para satisfacer una necesidad social reconocida estamos hablando de 'profesiones'. La gestión del conocimiento es una tarea profesional que utiliza como instrumento el conocimiento creado por los investigadores. Que sea vista esa tarea como una función más de la profesión de profesor universitario que implica por el momento funciones de docencia, investigación, gestión administrativa y representación institucional, es algo que no se puede establecer sin más. No hay coste cero en esta atribución y tampoco es de recibo desde el punto de vista de la competencia a utilizar que se habilite una forma de evaluar la transferencia de conocimiento y que no se haya habilitado antes un programa de formación de profesores, para el logro de las competencias se 
requieren para hacer la transferencia. No es lo mismo, y es un error grosero de consecuencias injustas para el mérito y la competencia, no distinguir entre conocimientos transferibles, creados por los profesores de universidad en el ejercicio de sus funciones profesionales, y transferencia de conocimiento, que es una tarea especializada, distinta de la crear conocimiento (Touriñán, 2018; Luque, 2018; Astigarraga, 2019; Fraser y Dunstan, 2010).

Conocer, enseñar, investigar, gestionar académicamente, y representarse a sí mismo y a los demás en la comunidad universitaria y crear conocimiento, son funciones acrisoladas de los profesores de universidad. Incluso cabe admitir que la difusión del conocimiento en revistas, congresos, simposios, prensa escrita y mundo digital son formas de transferencia que van asociadas al conocimiento creado. $Y$ también va asociado al conocimiento su aplicación. Pero, cuando hablamos de transferencia, no estamos hablando de aplicación de mi conocimiento, sino de encontrar las vías eficaces de crear una necesidad de esa aplicación o hacer ver esa necesidad a los receptores de la red de transferencia. Eso es algo nuevo que tenemos que aprender a hacer, individualmente, en unos casos, y colectivamente como facultad, en otros, porque la transferencia no es igual en cualquier área y disciplina. No debemos ignorar que, desde la perspectiva de la transferencia de conocimiento la cultura de la innovación no es un fin en sí misma, es un medio para satisfacer una necesidad social desde el conocimiento creado y, por tanto, cada institución tiene que identificar los valores éticos y sociales que sostienen su propia cultura de la innovación y a qué desarrollos empresariales, sociales y culturales productivos se orienta la transferencia y todo ello sin dejar de ver que la diferencia entre intereses individuales y de la organización en cuanto a la transferencia son un problema de poder (Touriñán, 2016, Martínez, 2008; Bermejo, 2018, Ramos, 2019; García, 2019; Luque, 2018; Astigarraga, 2019; Fraser y Dunstan, 2010).

El volumen de conocimiento que ya se ha producido en torno a la gestión del conocimiento y su transferencia, podemos afirmar que no cabe ninguna duda de su carácter especializado y específico. La planificación de la transferencia de conocimiento creado ya permite distinguir ocho fases, que no necesariamente se siguen en el orden previamente especificado; más bien conforman un ciclo que se reinicia para continuar avanzando a modo de espiral en ciclos derivados de mejora permanente (Ortega, Ramírez, Torres, López, Servín, Suárez y Ruiz, 2007, p.167) (Cuadro 7).

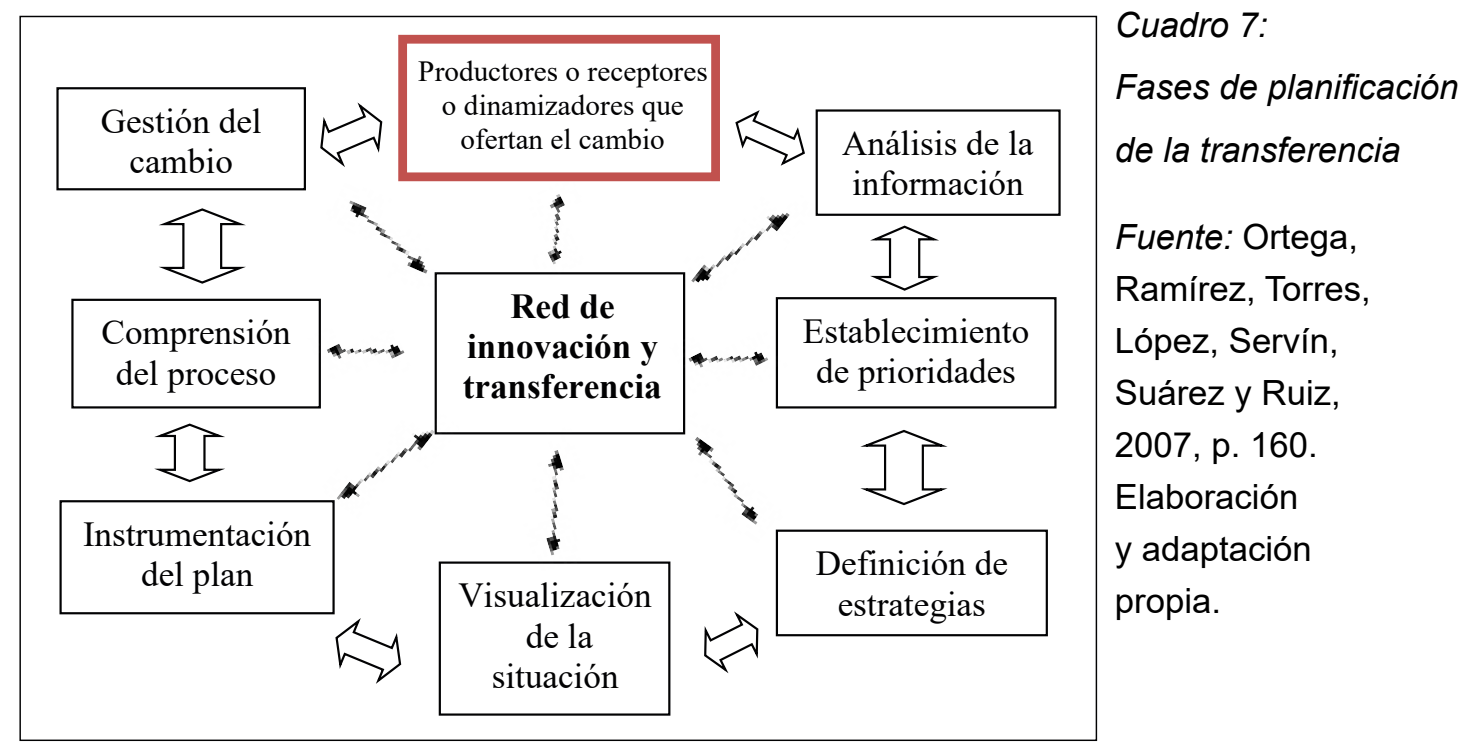


3. LA TRANSFERENCIA DE CONOCIMIENTO ORIENTADA A LA INNOVACIÓN SOCIALEXIGE RELACIONAR CIENCIA-TECNOLOGÍA Y SOCIEDAD

En palabras de la UNESCO, la noción de sociedad de la información se basa en los progresos tecnológicos. En cambio, el concepto de sociedades del conocimiento comprende dimensiones sociales, éticas y políticas mucho más vastas. El hecho de referirse a sociedades, en plural, no se debe al azar, sino a la intención explícita de la Unesco de rechazar la unicidad de un modelo "listo para su uso" que no tenga suficientemente en cuenta la diversidad cultural y lingüística, único elemento que nos permite a todos reconocernos en los cambios que se están produciendo actualmente. Hay siempre diferentes formas de conocimiento y cultura que intervienen en la edificación de las sociedades, comprendidas aquellas muy influidas por el progreso científico y técnico moderno. No se puede admitir que la revolución de las tecnologías de la información y la comunicación nos conduzca -en virtud de un determinismo tecnológico estrecho y fatalista- a prever una forma única de sociedad posible (UNESCO, 2005, p. 17; UNESCO, 1997).

Las sociedades del conocimiento no se reducen a la sociedad de la información. El nacimiento de una sociedad mundial de la información como consecuencia de la revolución de las nuevas tecnologías no debe hacernos perder de vista que se trata sólo de un instrumento para la realización de auténticas sociedades del conocimiento. El desarrollo de las redes no puede por sí solo sentar las bases de la sociedad del conocimiento, que debe ser vertebrada sobre los pilares de la diversidad creativa, la educación permanente, la libertad de expresión y la solidaridad digital, tomando como bases de trabajo, la formación, la cooperación, la investigación y la innovación (UNESCO, 2011 y 2005) (Cuadro 8).

\section{Cuadro 8: Triángulo de la sociedad del conocimiento}

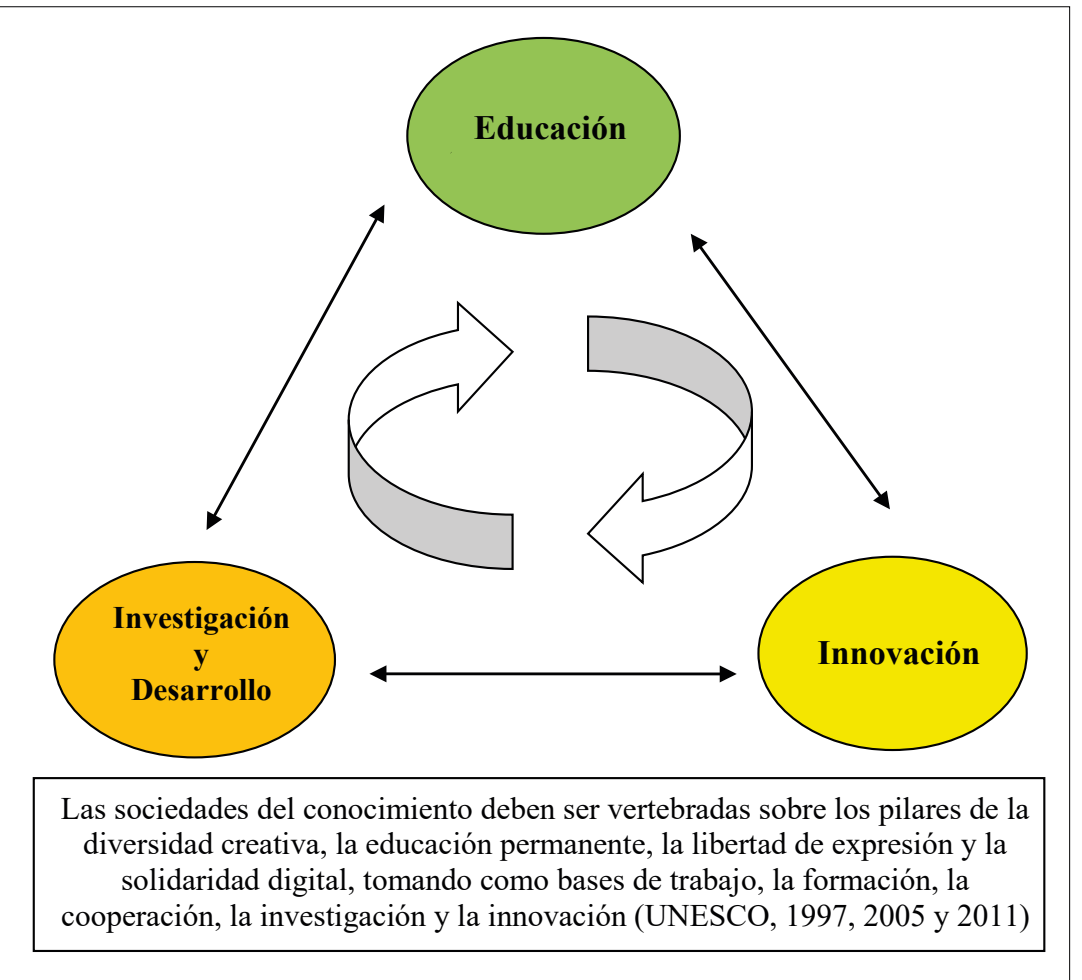

Fuente: Potocnik, 2005; Bueno, 2006; UNESCO, 1997. Elaboración propia. 
La noción de "sociedad del conocimiento" fue utilizada por primera vez en 1969 por un Peter Drucker y para la UNESCO, no es una noción totalmente ajena a la idea de sociedad postindustrial, a la idea de sociedad del aprendizaje y a la idea aprender a ser y a la idea de sociedad educativa (Bell, 1973; Drucker, 1969; Faure, 1973; Husén,1978; Hutchins, 1969). Posteriormente, en la década de los 90 se añaden a estas ideas la de las redes de universidades emprendedoras de Clark y Gibb (Clark, 1998; Gibb, 1993), que fueron reforzadas por los trabajos pioneros de Gibbons, Ziman y Slaughter y Leslei (Gibbons y otros, 1994; Ziman, 1994; Slaughter y Leslie, 1997). De manera que el contenido básico de la idea de sociedad del conocimiento quedaba establecido al incorporarse la idea de la universidad como agente con protagonismo especial en la relación universidad-empresa-estado-sociedad civil. La ciencia se convierte en cuestión de estado y la innovación y la educación son los fermentos de la nueva forma de relación (Touriñán, 2016).

En las sociedades del conocimiento, la ciencia, la tecnología y la sociedad de la información con su impronta de globalización hacen que las palabras desarrollo, progreso y "occidentalización" se equiparen intencionalmente, corriendo el riesgo de generar propuestas de desarrollo que impongan las soluciones particulares de occidente a cualquier país en cualquiera de sus circunstancias. La cuestión clave es -como ha definido la Sociedad para el Desarrollo Internacional en su Congreso mundial celebrado en Santiago de Compostela en 1997- responder a la pregunta qué tipo de globalización queremos, porque la globalización debe ser un instrumento para reforzar el compromiso cívico a favor de las identidades culturales regionales y los desarrollos creativos (SID, 1997).

Cada vez cobra más fuerza la propuesta de defender la existencia de sociedades del conocimiento en el mundo globalizado, frente a la existencia de la sociedad del conocimiento en ese mundo, pues parece evidente que la implantación de un modelo uniforme a escala planetaria no responde a la verdadera historia de nuestros tiempos, ni al sentido de la diversidad creativa (SID, 2000; UNESCO, 1997).

Desde esta perspectiva, el factor de producción absolutamente decisivo ha dejado de ser el capital o el suelo o la mano de obra; ahora es el saber. El valor en la nueva sociedad se crea mediante la innovación y la productividad; ambas son aplicaciones del saber al trabajo y esa relación con el conocimiento favorece el carácter abierto de la sociedad del conocimiento.

La consideración de la falta de conocimientos como uno de los mayores problemas del desarrollo supone un tipo de discurso en el que todavía participan pocos y que, además, acostumbran a estar lejos de las esferas de influencia. Los países más desarrollados hacen énfasis en la tecnología y en el conocimiento para poder competir. Paradójicamente, en el día a día hay discursos orientados a hacernos creer que los únicos factores que influyen en la competitividad son los costes salariales y del capital, ignorándose que los conocimientos tienen un papel tan importante como esos factores. La información disponible sobre el límite a la competitividad producida por el déficit de conocimientos es abundante. Sólo a modo de ejemplo, recordemos que un estudio ya clásico del IRDAC dice que el resultado de los sistemas de enseñanza y formación (incluida especialmente la enseñanza superior), en términos tanto de cantidad como de calidad de las calificaciones a todos los niveles, es el primer determinante del nivel de productividad industrial y, por lo tanto, de competitividad de un país (Telford, 1990).

En esta industria del conocimiento, las ideas adquieren la condición de materia prima. La tendencia clásica del desarrollo tiende a apoyar una Ciencia susceptible de aplicación 
en el sistema productivo; las tendencias más avanzadas en el ámbito de la innovación apuntan a lo contrario: atender al diseño de un sistema productivo capaz de incorporar, en el corto plazo, los desarrollos de la investigación fundamental al ritmo que se producen en la actualidad. $\mathrm{Y}$ en este debate, es preciso tener muy claro que el conocimiento, la Ciencia y el propio hombre, deben afrontar la disyuntiva de incorporarse o alejarse cada vez más de los caminos que se abren al desarrollo. Obviamente, la solución, si la hay, habrá que buscarla también desde la educación y esto hace que el Sistema conocimiento-educacióninnovación adquiera un significado específico en la universidad del momento.Descubrir e inventar son dos conceptos que dan contenido significativo al conocimiento por su relación con el desarrollo tecnológico.

La evidencia de transformación de la realidad por medio de la intervención humana enfatiza el uso apropiado del conocimiento hacia la creación, la innovación y la tecnología, lo cual pone de relieve la importancia del Sistema investigación- desarrollo tecnológico-innovación (Messadié, 1999, 2000a y 2000b). Hemos de aprender a descubrir, innovar e inventar para conocer y transformar la realidad y nuestros contextos y eso debemos hacerlo con criterio formal de aprendizaje y con impronta de huella personal creativa. Nada de eso se consigue sin actuar intencionalmente en la educación para articular relaciones entre inteligencia, cognición, afectividad y creatividad. La tecnología y la innovación tecnológica identificada en procesos y productos que han producido una nueva impronta, una huella duradera, en la creación de conocimiento son la base del desarrollo, que no es un asunto de empresa privada simplemente o de la universidad, es una "Cuestión de Estado" y esto quiere decir que la ciencia y la educación se convierten en objeto de la política (Touriñán, 2008; Martín y otros, 1986; Hidalgo, León y Pavón, 2002).
El conjunto universidad-investigación-innovación es eje de determinación de decisiones en la política científica y en la política educativa por la implicación de la universidad en la formación y en la investigación. Entre la investigación y la universidad hay una unión especial que la convierte en instrumento estratégico de innovación (Touriñán, 2000):

- La Universidad, en general, constituye una fuerza investigadora muy grande.

- Esta fuerza investigadora no tiene que disminuir, dado que hay una relación inequívoca entre calidad de la enseñanza universitaria y calidad de las actividades de investigación y desarrollo tecnológico (IDT) en las instituciones de enseñanza superior.

- La enseñanza superior puede contribuir de manera significativa al desarrollo regional, tanto por su virtualidad formativa en la investigación, como por su capacidad de innovación tecnológica. La presencia de la enseñanza superior en una región representa una inversión hacia el futuro; proporciona mano de obra altamente cualificada y constituye una fuente de conocimiento, asesoramiento e investigación utilizable por la empresa y la industria.

Esta relación entre investigación y comunidad universitaria es importante para el sistema ciencia-tecnología-sociedad y mediatizadora del desarrollo tecnológico, de tal manera que buena parte de su éxito en el desarrollo regional depende de que se alcance un nivel de comprensión general de la ciencia y de la tecnología en la sociedad, suficiente para servir de base a la difusión rápida y generalizada de las innovaciones y de la nueva tecnología.

Y en este marco de dependencia, la relación entre la empresa y la enseñanza superior es significativa para el conjunto universidadinvestigación-empresa: 
- Las instituciones de la enseñanza superior deberían considerar la cooperación con la industria como una parte fundamental de su misión, estando a favor de la adaptación de sus estructuras para poder realizar la colaboración.

- Las empresas deberían formular, ante sus órganos representativos, políticas positivas para fomentar la colaboración.

- Las Administraciones tienen que adoptar políticas de incentivos que estimulen la inversión de las empresas en la formación, en la investigación, y en el desarrollo.

Todas estas condiciones confirman el énfasis en el desarrollo de la sociedad del conocimiento y la importancia de reparar en los ejes estratégicos, relacionados con la educación, que afectan a la innovación (Cuadro 9):

- Sistema ciencia-tecnología-sociedad

- Sistema investigación-desarrollo tecnológico-innovación:

- Conjunto universidad-investigaciónempresa

- Conjunto universidad-investigacióninnovación

- Sistema conocimiento-educacióninnovación, que está vinculado a los procesos de cambio y a la escuela. 
Cuadro 9: Sociedad-Estado-Ciencia- Educación-Innovación-Transferencia en las sociedades del conocimiento

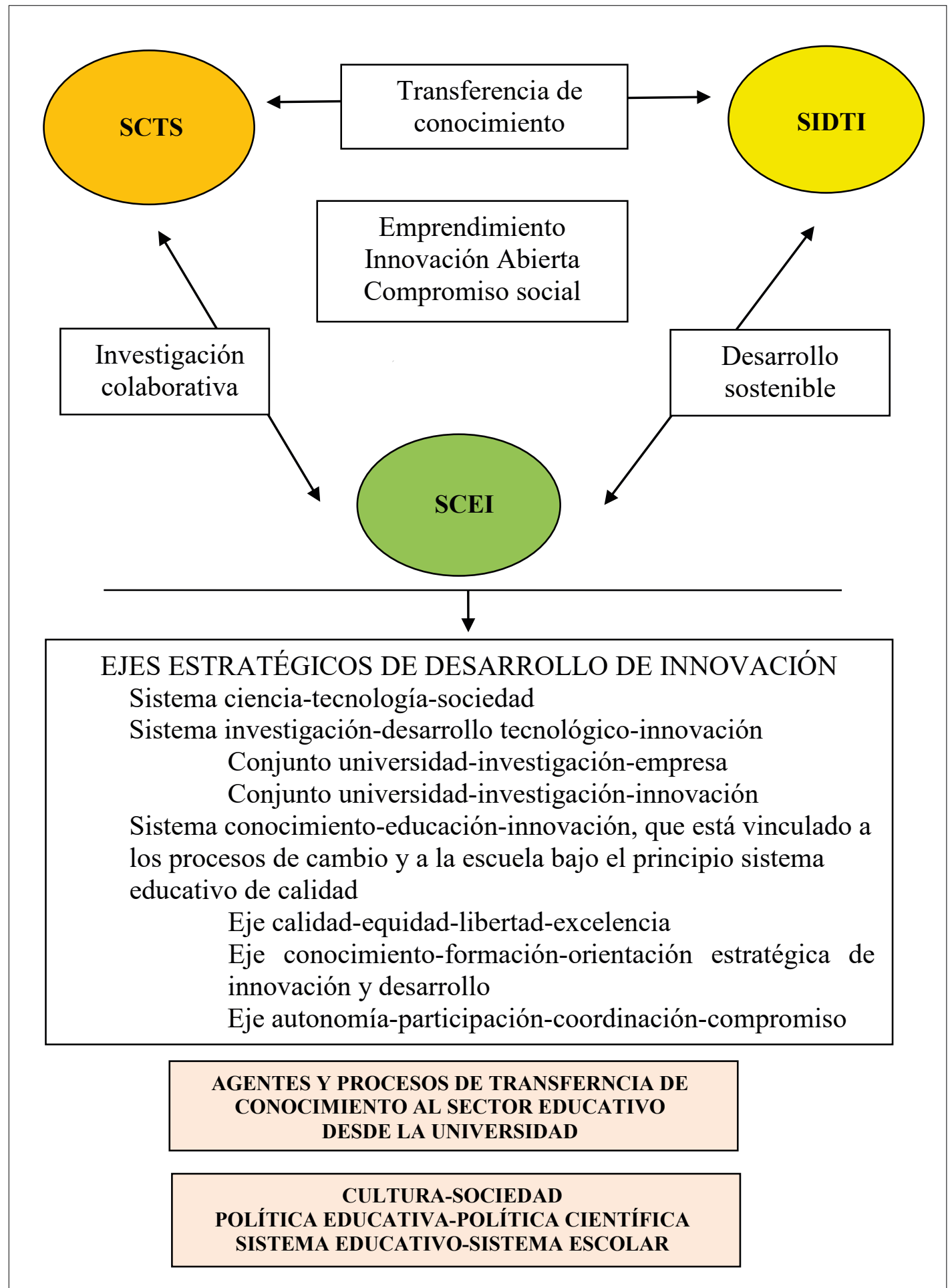

Fuente: Touriñán, 2016. Elaboración propia. 
La Unión europea se hizo eco de esta nueva universidad y sociedad en el Libro blanco de la educación y de la formación (Comisión Europea, 1995) y en 2005 se incorpora abiertamente a la idea de la nueva universidad innovadora y emprendedora bajo el lema "Construir la Europa del Conocimiento para el Crecimiento" y se concretó en la metáfora gráfica del "triángulo de la sociedad del conocimiento en Europa" que hace especial énfasis en el papel de la educación en cualquiera de los niveles de enseñanza con el objeto de armonizar innovación y trabajos de I+D (Touriñán y Sáez, 2015; Comisión Europea, 2004 y 2005, Bueno, 2007).
La tercera misión se basa en dos grandes objetivos: por un lado, la responsabilidad social institucional de la universidad; $y$, en segundo lugar, el compromiso de transformar el conocimiento en valor económico, incidiendo en la competitividad y facilitando la innovación, la creatividad y el desarrollo cultural, social, científico y tecnológico (CRUE, 2018; Vilalta, 2013; Touriñán, 2000; Touriñán y Bravo, 2000; Touriñán y Sáez, 2015). La tercera misión, apunta a Innovación Abierta, Emprendimiento, Cooperación social, Desarrollo sostenible, Transferencia de conocimiento y Formación (Cuadro 10).

\section{Cuadro 10: Tercera misión de la universidad}

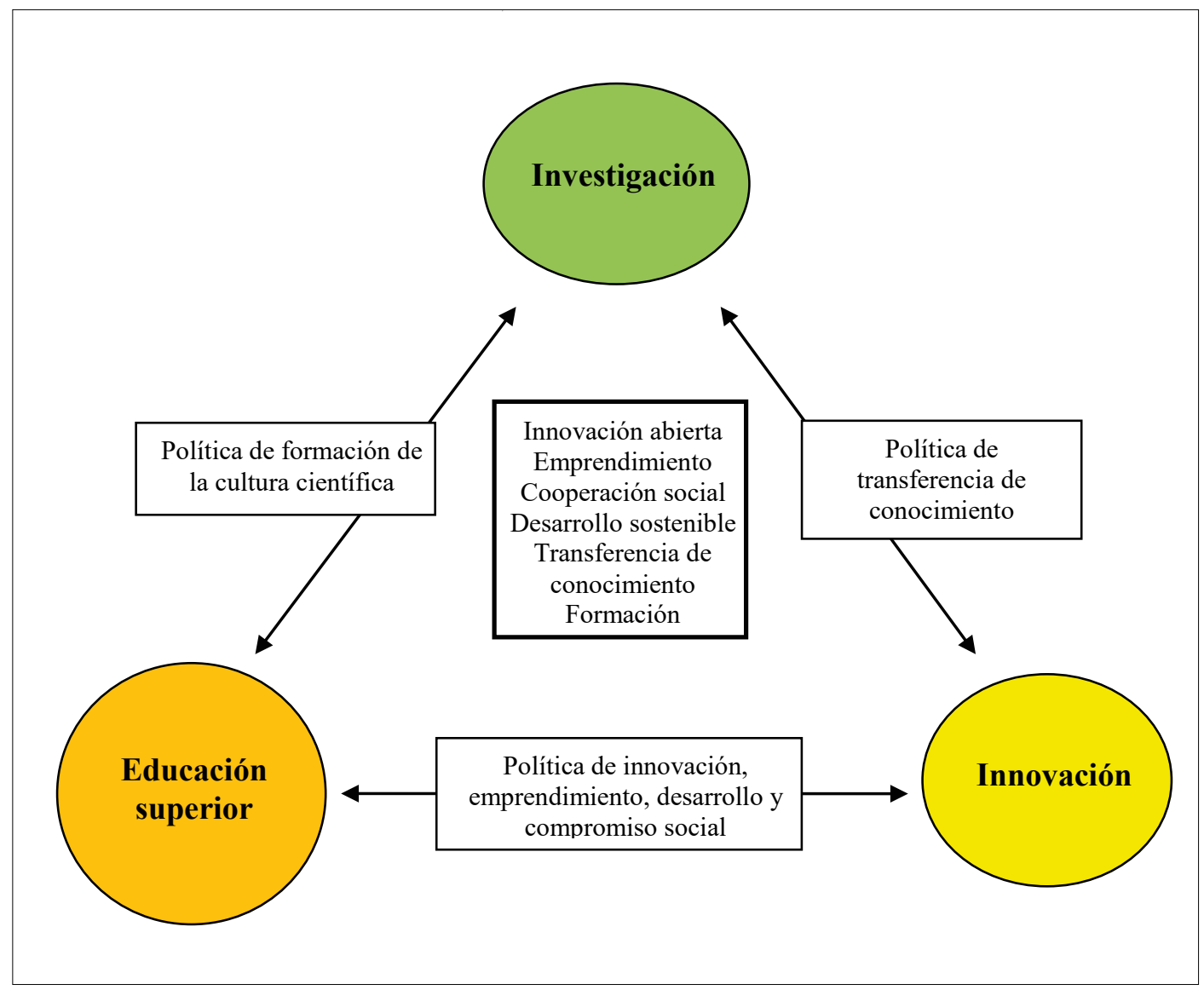

Fuente: Fuente: Potocnik, 2005; Bueno, 2007; Touriñán, 2016. Elaboración propia. 
Pretender reducir la tercera misión a un problema de valor económico del conocimiento, obviando la función de responsabilidad social de la universidad y su implicación en el desarrollo cultural y social, cercenando la misión tradicional de la universidad de desarrollo social y cultural, productivo y crítico, es no entender que los modelos integrados referidos al modo de producción del conocimiento han evolucionado desde la hélice de triple pala a modelos de cuatro y cinco palas que siempre han venido a reforzar, como hemos visto en el epígrafe anterior, la idea de que ningún modelo es puro y que el modelo es el que debe ajustarse a la realidad y no al revés, de tal manera que la relación entre innovación, emprendimiento y cooperación social es integral en los modelos avanzados con red responsable de la transferencia y la sociedad civil no es un apéndice en esa relación.

En definitiva, como hemos visto en el epígrafe anterior, en el modelo de transferencia están unidos emprendimiento cultura, sociedad, cooperación y sostenibilidad, asumiendo las posiciones generales de la Unión Europea sobre innovación y desarrollo. $Y$ esa relación integrada, como acabamos de ver en este epígrafe, responde además a las posiciones asumidas por la UNESCO, respecto de las sociedades del conocimiento desde los sistemas ciencia-tecnología-sociedad, conocimientoeducación-innovación, investigación-desarrollo tecnológico-innovación. $Y$ dicho esto, también conviene resaltar que, reducir la figura de lo cultural, lo social y lo cooperacional a un transversal respecto del emprendimiento, en la tercera misión de la universidad y en la transferencia de conocimiento y su singularidad en cada caso, es hacerle un flaco favor a esos términos, porque lo mismo podría decirse de la ciencia, la investigación y el emprendimiento. Todas son funciones importantes igualmente en la tercera misión y todas son transversales o todas son singulares en relación con el desarrollo y la innovación, pero ninguna queda subalternada a las otras (Conesa, 2019).

\section{EN ESPAÑA, LA LEY VALORA LA TRANSFERENCIA MUCHO MEJOR QUE LAS RESOLUCIONES QUE CONVOCAN A EVALUACIÓN Y PUBLICAN LOS CRITERIOS DE EVALUACIÓN ${ }^{2}$}

En el BOE de 26 de noviembre de 2018 (número 285) se publica la Resolución de 14 de noviembre de 2018 de la CNEAI (Comisión evaluadora de la actividad investigadora) por la que se hacen públicos los criterios específicos de los campos de evaluación de la actividad investigadora de los profesores universitarios y del personal investigador funcionario de los organismos públicos de investigación. La existencia de esa Resolución me obliga a plantearme si debe ajustarse la transferencia a los cuatro bloques de criterios que se consideran en la evaluación y si eso que establecen los criterios forma parte de la actividad ordinaria de los profesores https://www.boe.es/boe/dias/2018/11/26/pdfs/ BOE-A-2018-16138.pdf.

Me sorprendió que, en esa Resolución, a partir de la página 115218, después de haber enunciado todos los criterios de evaluación relativos a la actividad investigadora para los 11 Campos de investigación reconocidos oficialmente, se añadieran cuatro páginas (hasta la 115222), dedicadas a la transferencia de conocimiento bajo el título de "Transferencia de conocimiento e innovación" sin numerar como campo específico, pero sin que por ello se deba considerar tratado como un Apéndice. Más bien parece que es un sexenio más, pero sin sus derechos.

Pero me sorprendió mucho más que esa

$2 \quad$ El 26 de febrero de 2019 se ha celebrado en Santiago de Compostela, en la Facultad de Ciencias de la Educación, el Simposio de carácternacional "La transferencia de conocimiento en educación. Un desafío estratégico". Participé en ese Simposio como invitado y desarrolle una ponencia, cuyo título es Transferir conocimiento al sector educativo desde la universidad: agentes y procesos implicados. Buena parte del contenido de este epígrafe se corresponde con las conclusiones de esa ponencia. 
Resolución se hiciera pública antes de que saliera una Resolución de la Secretaría de Estado abriendo el proceso de solicitud de evaluación de la actividad investigadora. En el BOE número 289 de 30 de noviembre de 2018 se publica la Resolución de 28 de noviembre de la Secretaría de Estado de Universidades, Investigación, Desarrollo e Innovación por la que se fija el plazo y procedimiento para la presentación de solicitudes de evaluación de la ACTIVIDAD INVESTIGADORA (eso es lo que dice expresa y exclusivamente el título) a la CNEAI. En el texto de la Resolución de la Secretaría de Estado -que es posterior en fechas de BOE y Resolución a la de la CNEAI-, se habla expresamente de la evaluación de la actividad investigadora y solo en dos ocasiones de transferencia (en el punto 1 y en el punto 2.4) https://www.boe.es/boe/dias/2018/11/30/pdfs/ BOE-A-2018-16379.pdf :

"El propósito de esta convocatoria es reconocer los méritos en la actividad investigadora desarrollada por el Profesorado universitario y por el personal de los organismos públicos de investigación de la Administración General del Estado, e incentivar su ejercicio y su calidad. En el supuesto de evaluación de la transferencia de conocimiento, y en la medida que se trata de un proyecto piloto para el año 2018 , los interesados sólo podrán solicitar un tramo de seis años" (BOE, 289, p. 118041).

"2.4. Los Profesores e investigadores antes mencionados que soliciten un tramo de transferencia de conocimiento (proyectopiloto) deberán haber obtenido un tramo de investigación antes del 31 de diciembre de 2018" (BOE, 289, p. 118042).

Mi sorpresa responde, pues, a la parca referencia que la política científica hace respecto de la transferencia que es un asunto y objeto que se considera el eje central de la trascendente misión de la universidad a favor del desarrollo social productivo y crítico. Pero no es solo un problema de frecuencia de nombre, sino un problema serio de identidad de la transferencia y de lo que se pretende con ella.

Mi sorpresa es expresable en dos preguntas:

¿Si el sexenio de transferencia es como los de investigación, por qué no tiene el mismo reconocimiento? (no tiene traducción económica)

¿Si la actividad de transferencia no es la de investigación científica, por qué se publica en medio de la actividad investigadora? ¿Y por qué solo es evaluable, si ya se tiene un sexenio de investigación? ¿Es que sólo se valora la transferencia de conocimiento previamente investigado por cada investigador? ¿No es posible transferir conocimiento científico no investigado por uno mismo?, y, en ese caso, ¿por qué los seminarios de difusión del conocimiento y las coordinaciones de grupos y la formación de doctorandos es transferencia?

Y esto me lleva a una pregunta más de carácter fundamentante en la política científica que debe justificar la convocatoria de transferencia:

¿Es la transferencia un asunto de investigadores individualmente considerados, o un asunto institucional colectivo, o ambas cosas a la vez?

¿Y si son distinguibles ambas categorías, es una actividad normal del investigador, o es una función específica y especializada? ¿Y cómo es que se evalúa la transferencia de los profesores, sin haberlos formado previamente para ello y cómo es que lo adecuado es evaluar un tramo de seis años?

¿No merecería la transferencia una convocatoria específica y singular como experiencia piloto que quiere reflejar la importancia que la política científica le otorga a la función de transferencia?

Estas son las cuestiones que a mí se me han generado al leer las Resoluciones, después 
de haber trabajado el texto de mi artículo. Y dado que así ha sido, no quería dejar de hacer alusión a ello, compartiéndolo, puesto que la transferencia es el tema central del trabajo.

Estoy convencido de que hasta hace muy poco, casi ningún profesor de universidad se preocupaba de la transferencia de conocimiento en términos de desarrollo productivo y nunca las oficinas mediadoras de transferencia de la universidad han buscado el modo de que el trabajo de cada investigador pudiera ser transferido. Ahora, además de los organismos de transferencia OTRIs-OTTs y los organismos públicos de investigación (OPIs) y los mediadores de la transferencia, al menos 17000 profesoresinvestigadores están pendientes de este tema (son los que, según la Secretaría General, se han presentado al sexenio de transferencia).

Creo que la transferencia de conocimiento requiere un tratamiento más acorde $\mathrm{y}$ singularizado, dada la importancia que tiene la misión de la universidad de desarrollo social, cultural y económico, productivo y crítico, que es la misión dentro de la que se encuadra la transferencia.

Para mí, el sexenio de transferencia nace, políticamente, con provisionalidad (nace a título de ensayo y experiencia piloto), sin clara consulta de abajo arriba respecto del contenido evaluable, y sin responder a criterio político acreditado. Si ustedes entran en el video de You Tube en el que se recoge la explicación del Secretario General de Universidades, verán que no hay explicación respecto de la prioridad, la oportunidad y el consenso que son los criterios básicos de la decisión en política científica. En el minuto 25.40 del video se escucha perfectamente que el Secretario General dice que en una comida con la Secretaria de Estado, y la Directora General, ellos tres fijaron, 'para lo bueno y para lo malo' (sic.) los criterios a partir de una larga lista que les entregó Salustiano Mato (intervención del Secretario General disponible en https://www. youtube.com/watch?v=t 9uimXgTRM).

Esta declaración exculpa de responsabilidad en la Resolución al asesor y catedrático Dr. Salustiano Mato, que generó un documento que la CRUE ha circulado en su asamblea $y$, aunque no ha sido sometido a aprobación de la asamblea, ha servido de base al Secretario General para establecer su listado de criterios de evaluación del tramo de transferencia (CRUE, 2018, p. 5). Es, por tanto, responsabilidad a los tres políticos haber determinado que la transferencia será evaluada atendiendo a cuatro bloques de criterios (Resolución 14 de noviembre de 2018 , ya citada):

1. Transferencia a través de la formación de investigadores. En este apartado se incluirán actividades y proyectos que fomenten, por un lado, la formación de investigadores $\mathrm{y}$, por el otro, la cultura emprendedora, a través de la creación de «start-up o spin-off». Se tendrá en cuenta el tipo de actividad, grado de participación de la persona solicitante, indicios de calidad, entidades colaboradoras o financiadoras, número de personas beneficiadas $\mathrm{y}$ resultados de la actividad.

2. Transferencia del conocimiento propio a través de actividades con otras instituciones. En este apartado se valorarán y evaluarán las fórmulas contractuales que correspondan y resulten válidas en Derecho; por ejemplo, como ocurre en el caso de las comisiones de servicios, de los servicios especiales o de las excedencias según la aplicación de la normativa estatal, autonómica y universitaria en vigor.

3. Transferencia generadora de valor económico. Este bloque pretende identificar aquellos indicadores que, por su impacto, generan mayor riqueza y tienen capacidad tractora en el territorio o en el seno de la comunidad a la que van dirigidos, como 
puede ser, por ejemplo, en términos de facturación de derechos de la propiedad intelectual $o$ industrial en los distintos campos del saber: ciencia, patrimonio, tecnología, artes, etc.

4. Transferencia generadora de valor social. Se incluyen aquellas actividades que redundan en el beneficio de la sociedad civil y en sus distintos grupos de interés. Se valorarán aspectos relacionados con la proyección externa y con la consolidación de la imagen pública universitaria.

Para mí, este sexenio no es como los de investigación, aunque se publica en el texto de los sexenios de evaluación de la actividad investigadora, pero genera la expectativa de que habrá que pagarlo y considerarlo como sexenio en orden a la excelencia (en el País Vasco, en los órganos de evaluación autonómicos, ya se decía antes de que se publicara la Resolución que se pagaría ese sexenio) y dado que no hay transferencia prevista a las Comunidades para ese pago, se está generando una expectativa y una presión financiera en las Comunidades que no podrá ser satisfecha, sin quebranto presupuestario en las arcas autonómicas y todo ello sin mediar acuerdo con las autonomías para esta actividad.

A la vista del texto y del procedimiento, casi podría pensarse que la motivación no explícita es recuperar por la vía del sexenio de transferencia la posibilidad de evaluar muchos trabajos de asesoría que abogados e ingenieros y economistas y otros profesores de universidad han realizado y no fueron evaluados positivamente como trabajos de investigación.

Creo que todo lo que sea recuperar evaluaciones perdidas o mal planteadas es bueno para la comunidad científica. Pero colar el sexenio de transferencia, incluso como experiencia piloto, sin haber sido sometido el texto a consulta previa de la comunidad universitaria y de los grupos implicados y sin distinguir entre transferencia individual de cada investigador y transferencia institucional (es obvio que los criterios no son iguales y que los criterios de los sexenios y los planes de estudios siguieron un procedimiento de legitimación política y académica totalmente distinto, implicando de abajo arribaba a la comunidad), suena más bien a oportunismo político respecto de una necesidad sentida que a rigurosa determinación política de satisfacer la necesidad. Se ha creado la fórmula de evaluación de la transferencia de conocimiento y no se han puesto las bases para formar a los profesores en la competencia para transferir. Se da por hecho que la universidad, institucionalmente tiene transferencia y que eso es una competencia de los profesores sin mediación especializada para desarrollar y aplicar modelos de transferencia (Touriñán, 2008).

Dicho esto, reitero que el contenido del artículo fue desarrollado con anterioridad a la publicación de la resolución del sexenio de transferencia, si bien el contenido que yo he trabajado puede servir para analizar el contenido de la Resolución del sexenio de transferencia, que no cambiará este año y se aplicará con racionalidad políticoadministrativa a los solicitantes tal como está formulado en el BOE (con la salvedad de que lo que allí se dice son criterios orientativos y no excluyentes, según el texto).

Es mi opinión que la racionalidad políticoadministrativa no es coincidente, ni converge siempre con la racionalidad epistemológica; por eso una norma puede ser mala respecto de su contenido técnico. Y, en el caso de la Resolución afirmo no solo eso, sino que no se atiene a criterios reconocidos de racionalidad de la decisión política de prioridad, oportunidad y consenso. $\mathrm{Ni}$ se ha consensuado con la comunidad científica, ni con los agentes de la transferencia, se va de arriba, abajo. No se ha consensuado tampoco con las Comunidades autónomas que, sin la coordinación territorializada, se ven en 
la situación de asumir la presión de todos los que obtengan evaluación positiva para que se pague este "nuevo sexenio". No se respeta la diversidad creativa en el tema de transferencia de conocimiento, porque no se establecen criterios que permitan integrar a todas las áreas de conocimiento y campos científicos en igualdad de condiciones, atendiendo a las peculiaridades de la transferencia en cada área y campo (¿Cómo es posible que en los sexenios se reconozca la especificidad del campo de educación y en el de transferencia no haya criterios específicos o matizados para ese campo?). Hay una tendencia clara en la Resolución hacia criterios orientados a productividad económica del desarrollo, en detrimento y desequilibrio respecto de la misión de desarrollo social y cultural que se integran por derecho propio en la misión de la universidad de contribuir al desarrollo económico, cultural y social, productivo y crítico. No veo la prioridad de la Resolución, pero, por el contrario, sí parece que se ve en la resolución la huella del oportunismo propio de la política de hechos consumados. Se trata de ser los primeros en poner la "pica en Flandes", de manera que el gobierno actual aparezca como el que ha convocado el sexenio por vez primera (justo antes de disolver el parlamento y convocar elecciones, que era lo anunciado, cuando se convocó el sexenio). No veo que, políticamente, con la resolución, se haya atendido a la responsabilidad compartida que requiere y demanda un tema tan complejo como este. $\mathrm{Y}$ por todo esto, conviene dejar constancia en el punto de partida del discurso que:

1.- La política de hechos consumados es nefasta para implantar una nueva obligación en el sistema. En la Resolución no se descubre, ni prioridad, ni oportunidad, ni consenso, ni responsabilidad compartida, ni coordinación territorializada en lo que afecta al contenido. Y por si eso fuera poco, lo más duro para nosotros y negativo como pedagogos es que la diversidad creativa no queda reconocida por campos científicos en los criterios de evaluación de la transferencia. Todo apunta a que, entrar en el juego de la Resolución, nos hace partícipes de lo que no nos potencia como pedagogos, dado que no se contemplan criterios específicos de educación y nos hace responsables directos de la evaluación negativa de nuestra transferencia, si se diera ese caso, porque estaríamos asumiendo los criterios al solicitar la evaluación.

2.- Entrar en el juego de la Resolución es dar por bueno que no se debe distinguir lo que exige la transferencia de conocimiento como concepto distinto y que se está midiendo lo que se debe medir por transferencia. Frente a esa afirmación, debemos entender que se debe evaluar todo el conocimiento de los profesores con criterios vinculados a la innovación, que es lo que da sentido a la transferencia, incluso el que ya está evaluado como sexenio de investigación, pues pueden ser trabajos de potencial valor de transferencia.

3.- A la universidad se la tiene que evaluar institucionalmente como institución que genera transferencia de conocimiento y se deberían crear criterios institucionalizados de transferencia de conocimiento (como los de los rankings). Pero además se debe evaluar el potencial de transferencia del conocimiento creado por los profesores con criterios específicos vinculados claramente al potencial innovador. Conocimientos transferibles y transferencia de conocimiento son dos conceptos distintos que no deben usarse dando lugar a confusión. Los profesores son especialistas en crear conocimientos transferibles. Además de la evaluación institucional de la transferencia, se debe evaluar el trabajo científico individual de cada profesor por su valor potencial de transferencia.

En definitiva, no veo que se hayan respetado las condiciones propias de la complejidad estructural de la decisión en política educativa y científica. (Cuadro 11). 
Cuadro11: Acción política como decisión compleja culturalmente diferenciada

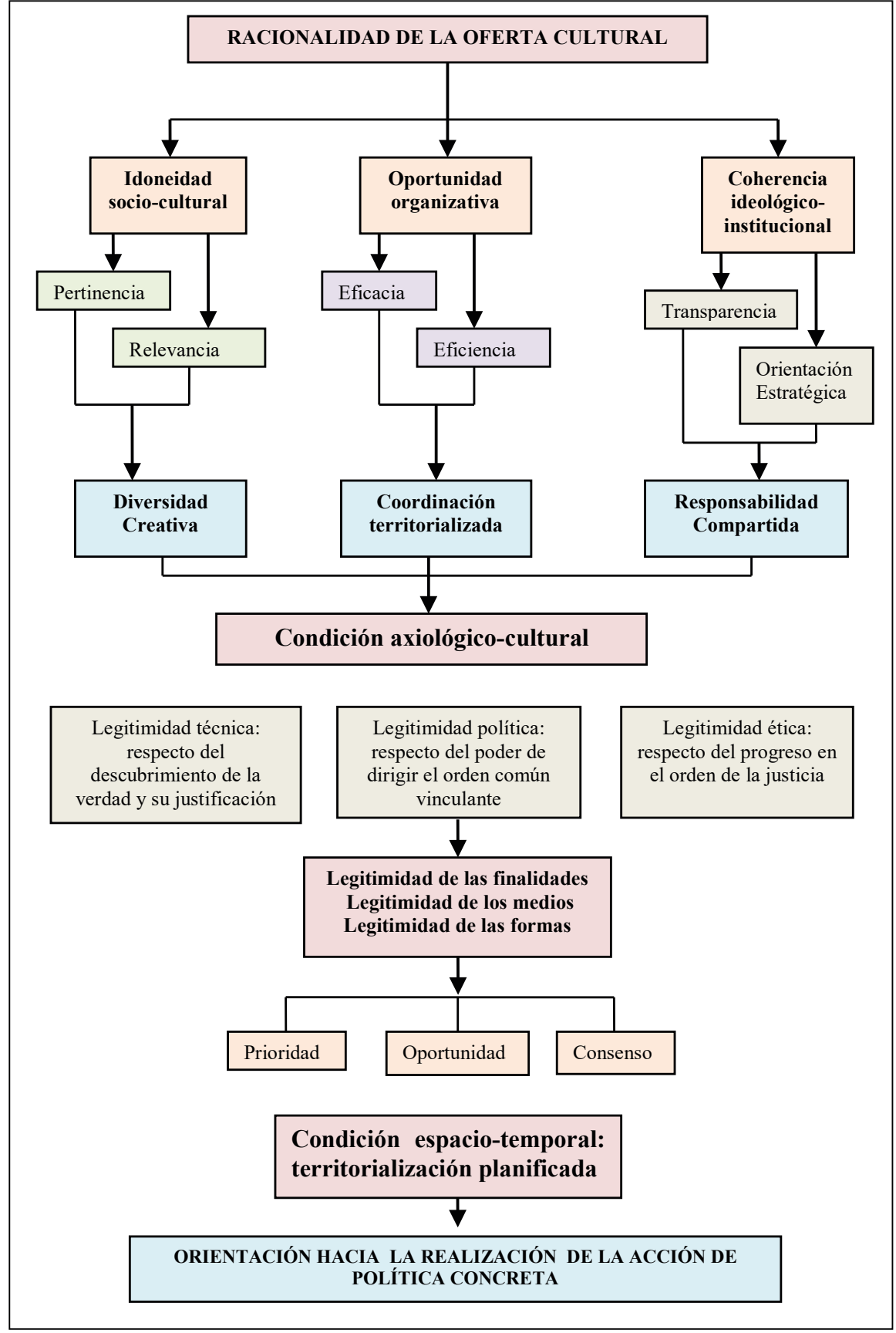

Fuente: Touriñán, 2017. Elaboración propia. 
A pesar de que en el Real Decreto-ley 3/2019, de 8 de febrero, de medidas urgentes en el ámbito de la Ciencia, la Tecnología, la Innovación y la Universidad, BOE $n^{\circ}$. 35, de 9 de febrero de 2019 (https://www.boe.es/boe/dias/2019/02/09/pdfs/ BOE-A-2019-1782.pdf ), solo se usa dos veces la palabra transferencia y solo como sustantivo que responde a una condición necesaria para cubrir la necesidad innovadora y emprendedora de la universidad en el ámbito económico, social y cultural, no quiero dar la impresión de que la ley no hizo nada respecto de la transferencia y por eso creo que es justo afirmar, antes de seguir con mi discurso, que la legislación ha dicho más de lo que se ha hecho. Creo que, en principio, debo decir que la ley valora mucho mejor la transferencia de conocimiento que las resoluciones que la ponen en marcha.

Así, la Ley de Universidades modificada, de 2007, contempla en diferentes artículos que (Ley Orgánica 4/2007, de 12 de abril, por la que se modifica la Ley Orgánica 6/2001, de 21 de diciembre, de Universidades. BOE 89, de 13 de abril de 2007, https://www.boe.es/boe/ dias/2007/04/13/pdfs/A16241-16260.pdf):

"La universidad desarrollará una investigación de calidad y una gestión eficaz de la transferencia del conocimiento y la tecnología, con los objetivos de contribuir al avance del conocimiento y del desarrollo tecnológico, la innovación y la competitividad de las empresas, la mejora de la calidad de vida de la ciudadanía, el progreso económico y social y un desarrollo responsable equitativo y sostenible, así como garantizar el fomento y la consecución de la igualdad".

"La vinculación entre la investigación universitaria y el sistema productivo, como vía para articular la transferencia de los conocimientos generados y la presencia de la universidad en el proceso de innovación del sistema productivo y de las empresas, prestando especial atención a la vinculación con el sistema productivo de su entorno. Dicha vinculación podrá, en su caso, llevarse a cabo a través de la creación de empresas de base tecnológica a partir de la actividad universitaria, en cuyas actividades podrá participar el personal docente e investigador de las universidades conforme al régimen previsto en el artículo 83 ".

En la legislación está expresada con claridad la valoración de la transferencia, hasta el extremo de definir, no solo la importancia y las consecuencias que se derivan de esta función, sino también la dedicación y reconocimiento que merece la transferencia:

"La transferencia del conocimiento es una función de las universidades. Estas determinarán y establecerán los medios e instrumentos necesarios para facilitar la prestación de este servicio social por parte del personal docente e investigador. El ejercicio de dicha actividad dará derecho a la evaluación de sus resultados y al reconocimiento de los méritos alcanzados, como criterio relevante para determinar su eficiencia en el desarrollo de su actividad profesional".

Y, por último, en la reciente Ley 14/2011, de 1 de junio, de la Ciencia, la Tecnología y la Innovación, en su Artículo 32, referente a la Dedicación del personal docente e investigador, establece que (Ley 14/2011, de 1 de junio, de la Ciencia, la Tecnología y la Innovación.BOE, 131, de 2 de junio de 2011; https://www.boe.es/ eli/es///2011/06/01/14/con):

"Las Universidades públicas, en el ejercicio de su autonomía, podrán establecer la distribución de la dedicación del personal docente e investigador a su servicio en cada una de las funciones propias de la Universidad"

A la vista de estos textos surgen preguntas y respuestas consecuentes que no están en consonancia con lo que las resoluciones dejan entrever: ¿Cómo es posible que no hayamos podido desarrollar un eficaz sistema 
de transferencia en cumplimiento del mandato legislativo? ¿Qué extrañas fuerzas hacen que sigamos hablando sobre la transferencia como la asignatura pendiente de las universidades? ¿Por qué no tenemos resuelto el desencuentro entre la universidad y la empresa? (Gómez Sal, 2016; Berbegal, 2017; Vilalta, 2016 y 2018; López-Varela, 2018; Luque, 2016; Rodríguez, 2017; Salaburu, 2017; Broncano, 2019; Vidal, 2018; Haug y otros, 2018; Barro, 2019).

Lo que yo he expuesto en este trabajo, me permite hacer las siguientes observaciones con criterio fundado en el conocimiento del tema y en relación con el conocimiento de la educación y su potencialidad como transferencia:

1.- La transferencia de conocimiento solo se entiende en relación con la innovación. Por eso, los criterios que se evalúen deben ser tamizados respecto de la innovación. Esto significa que los cuatro bloques de criterios de la Resolución de la CNEAI deberían reformularse atendiendo a transversales de innovación de proceso, de producto y de organización. Por ejemplo, si se consideran las tesis doctorales para la evaluación de la transferencia, la pregunta debe ser qué tesis aportó innovación de proceso, de producto o de organización. Los criterios, tal como se han formulado, no son criterios específicos para transferencia de conocimiento, sino indicadores en los que habría que razonar su valor de transferencia.

2.- La transferencia es institucional y es también individual. Los organismos institucionales no han hecho nada por ahora para dotar plazas en centros que sirvan de dinamizadores de la transferencia (algo que la ley da por sentado como necesario). Se ha evaluado al profesor como transferidor, antes de establecer programas de formación de dinamizadores de transferencia. El desamparo de los profesores universitarios ante este tema es grande y de graves consecuencias. Añadir funciones a la tarea profesional sin consenso previo y dar por supuesta la competencia en la nueva función, es demasiado suponer.

3.-Cada profesor crea conocimiento $y$, dado el sistema español de fomento de investigación y reconocimiento de tareas-funciones del profesor, no se puede plantear la transferencia como una función más al lado de docencia, investigación, representación ygestión. Deben definirse las condiciones de esa función y la preparación del profesor para el desempeño de la misma, si así se acuerda.

4.- El área de educación es específica. Si se ha reconocido su especificidad en los campos científicos de evaluación de sexenios por la CNAEI, no hay razón para negar la especificidad en la transferencia, salvo que se diga que la transferencia no es una función especializada y específica. Hay conocimientos transferibles $y$ hay transferencia de conocimiento. Se pueden evaluar los conocimientos transferibles de un profesor. Pero a nadie se le puede exigir transferencia, rigurosamente hablando, sin prepararlo previamente. La transferencia institucional es evaluable con criterios de Ranking, pero el conocimiento del profesor universitario, que es conocimiento transferible, debe ser evaluado en toda su extensión, como actividad científica y como potencial valor $\mathrm{d}$ transferencia. 
Se debe evaluar, por tanto, el potencial de transferencia del conocimiento creado por los profesores con criterios específicos vinculados también al potencial innovador. Conocimientos transferibles y transferencia de conocimiento son dos conceptos distintos que no deben usarse dando lugar a confusión. Los profesores son especialistas en crear conocimientos transferibles. Además de la evaluación institucional de la transferencia, se debe evaluar el trabajo científico individual de cada profesor por su valor potencial de transferencia. $Y$ esto no se resuelve con un sexenio de transferencia, sino con el ajuste de todo el conocimiento creado a su valor de transferencia de conocimiento, con independencia de que haya sido evaluado ya como actividad investigadora. Hay conocimiento que yo aplico y tiene valor de transferencia y difusión, aunque no sea una actividad investigadora en sentido estricto (por ejemplo, las traducciones de libros y artículos, las recensiones de textos y la actividad como juez ciego en los artículos de revistas científicas).

5. La tercera misión de la universidad, tal como ahora se viene definiendo, no es una misión nueva, sino la consecuencia de la misión de desarrollo económico, social y cultural, productivo y crítico, que se le exige a la universidad desde el siglo XX. Esta misión no cuestiona ni relega en importancia las misiones de estudio y profesión, que forman parte de nuestra universidad y que ahora parece que se colocan en orden de preferencia posterior respecto de docencia, investigación y transferencia, sin que los criterios de prioridad y ordenación se hayan explicitado previamente. Los departamentos son unidades de investigación y docencia. Las facultades son unidades de organización vinculadas al estudio, en los planes, y a las competencias profesionales que se logran, en la carrera. $Y$ eso no debe obviarse al plantear con visos de realidad la transferencia de conocimiento.

6.- La tercera misión no da lugar a una futura 'cuarta misión' orientada a evaluación de retornos y centrada, según la CRUE, en el impacto y en el alcance de los resultados que la investigación universitaria genera en la sociedad, en todos los ámbitos del conocimiento y en la actividad universitaria en general (CRUE, 2018). Evaluar no es una cuarta misión; es una parte del proceso de planificación. Debemos distinguir misiones y tareas derivadas $y$ funciones propias de profesores.

7.- La propuesta de criterios de evaluación de la transferencia es desequilibrada respecto del reconocimiento de los elementos que definen la transferencia y respecto de qué cosas pertenecen a la red de transferencia y cuales al trabajo individual del profesor. La propuesta de la Resolución se decanta hacia criterios que premian la actividad investigadora (quizá por eso prima en la Resolución la dedicación de tres bloques a la actividad científica y solo uno a actividad cultural y social) esto es tendencioso y perjudica la imagen de valor del conocimiento de cada Campo.

8.- La educación ha desarrollado mucho trabajo en innovación, gestión cultural y en desarrollo y es necesario premiar el valor de transferencia de conocimiento atendiendo a su especificidad. Las 
facultades de Ciencias de la educación y los ICES pueden desarrollar una labor imprescindible en esa tarea y provechosos proyectos en ese proceso.

Los conocimientos transferibles existen en todos los campos. La ley prevé que se formen y se creen puestos de transferencia. Los dinamizadores de la transferencia son necesarios, en la FACULTAD y en los ICE. Los profesores son especialistas en crear conocimientos transferibles. Además de la evaluación institucional de la transferencia, se debe evaluar el trabajo científico individual de cada profesor por su valor potencial de transferencia.

Aceptar lo que la Resolución establece como criterios de evaluación, es dar por bueno que no se debe distinguir lo que exige la transferencia de conocimiento como concepto distinto y aceptar que la universidad actúe con criterios de empresa en la transferencia y no con criterios de universidad. La universidad no puede transferir conocimiento a cualquier empresa y a cualquier precio, sin perder de vista su responsabilidad SOCIAL de servicio.

9.- Las ciudades educadoras, o las ciudades creativas, o las ciudades amigables con los mayores, o las ciudades sostenibles son grandes núcleos de transferencia desde educación que están siendo obviados en los criterios publicados y solo se está prestando una atención mínima al trabajo con ONGs en esos criterios.

10.- Si toda nuestra actividad transferible se traduce a los cuatro criterios de la Resolución, la mayor parte del conocimiento transferible de educación queda anulado o minimizado o minusvalorado o menospreciado.

11.- La política de hechos consumados no beneficia al conocimiento transferible. Los profesores se ven obligados a concursar para no ser menos que los otros que han solicitado ser evaluados en la convocatoria. Las Comunidades se verán obligadas a pagar el sexenio nuevo por la presión que ejercerán los solicitantes evaluados positivamente. La administración central no paga el sexenio evaluado positivamente, ni transfiere su importe a las Comunidades y, si se evalúa negativamente un sexenio de transferencia, el culpable y malo es el profesor, no el Estado, a pesar de quees este quien lo hizo mal en el desarrollo del proceso, ni la universidad, a pesar de que no ha contribuido a formar en transferencia. En este contexto, son solo los profesores los que pagan las consecuencias de una evaluación negativa.

12.- Sería necesario que la Conferencia de decanos de educación, cuya función principal es velar por los intereses de educación desde las facultades, por medio de los planes de estudios y las carreras, nos defendiera abiertamente y no aceptaran entrar en el juego de lo establecido por la Resolución sin que se definan previamente las delimitaciones del concepto de transferencia y los criterios que deberían ser tenidos en cuenta para no perjudicar las misiones de la universidad, ni los trabajos de los profesores, atendiendo a la especificidad de los campos científicos y a la especialización de la tarea de transferir, ni el singular papel de las 
investigaciones de educación en la innovación.

De no hacerse así, todo parece indicar que nadie va a reparar en que:

- el sexenio de transferencia no es tal sexenio, salvo por la duración común y artificiosa de seis años

- la evaluación del tramo de transferencia no tiene que depender necesariamente del requisito de tener un tramo de investigación evaluado

- la evaluación del tramo de transferencia debe hacerse bajo criterios vinculados a la innovación y con criterios que no oculten la especificidad de cada campo, ni minimicen la importancia del compromiso de la universidad con transferencia hacia el desarrollo social y cultural de servicio

- hay actividad transferible en el trabajo del profesor que no es su propia investigación

- la evaluación institucional de la transferencia de conocimiento de cada universidad no debe trasladarse automáticamente a los profesores

- loscriterios deTransferenciadeconocimiento no tienen que ser necesariamente los mismos para la universidad y para el profesor; hacerlos iguales es hacer que la evaluación negativa de un profesor sea su responsabilidad y la evaluación negativa de la universidad sea derivada a la evaluación negativa del profesor

- la Universidad dirige la acción hacia el evaluado y ella se ve liberada de culpa en un proceso en el que no ha trabajado lo que la ley establece respecto de la formación de profesores y de la contratación de personal específico para esa tarea entre los profesores, aparte de que acepta que los criterios de evaluación institucional de transferencia de conocimiento de profesores sean los mismos que para la universidad. Es obvio que los criterios se han fijado pensando en la tercera misión de la universidad y se aplican a los profesores y no a la universidad. Pero si hay evaluación negativa de un sexenio solicitado, el responsable de ello y el malo es el profesor, no la universidad, porque a él es al que se le imputa la evaluación negativa

- el Estado dirige la acción hacia el evaluado y aquel, con la convocatoria, se ve liberado de responsabilidad en un proceso en el que no ha hecho lo que la ley establece respecto de la definición, dotación y previsión para el desarrollo de la transferencia de conocimiento y su evaluación. Si se evalúa negativamente un sexenio de transferencia, el responsable de ello y el malo es el profesor, no el Estado, a pesar de que es este el que lo hizo mal en el desarrollo del proceso y no ha afinado como debe la evaluación.

\section{CONSIDERACIONES FINALES, A MODO DE CONCLUSIONES}

Cuando se trata de precisar el concepto de IDT, conviene recordar que, en un primer momento, se habló de investigación y desarrollo: I+D ( R+D, en la terminología anglosajona). Posteriormente, a la hora de determinar el gasto, se incorporó, tanto la evaluación, como la difusión de programas $(E+R D+D)$. En el momento actual, la innovación ya está también incorporada al proceso de I+D y se acepta que el esquema de evolución de la I+D es como sigue:

I+D (=R\&D)— E+RD+D— IDT (IDTi)

La difusión (D) se retira de la fórmula actual (IDTi) y se une a Transferencia de conocimiento (TrCo). El énfasis de conjunto está en el concepto de innovación, pero conviene recordar que en los últimos cincuenta años 
se han ido modificando las posiciones sobre ese concepto, que se ha convertido en un importante campo de conocimiento, ocupando a miles de investigadores. Hablar de innovación y transferencia sin asociarlo a conocimiento especializado y específico es una temeridad y una invitación a no mirar de frente el problema que se deriva de la formación de competencias para la transferencia y la gestión de conocimiento.

Se puede mantener, por consiguiente, que las políticas científicas que orientaron el gasto en I+D se vienen transformando en políticas científicas que, respecto de la innovación, orientan el gasto en IDTi, bajo una visión abierta (innovación abierta, ciencia abierta, sociedad abierta, etcétera). Todas estas situaciones de avance confirman que el énfasis en el desarrollo tecnológico supone defender tres cualidades especiales en el fomento de la investigación y en la política científica:

1) El valor estratégico de esta actividad

2) La modificación de la financiación y de la promoción de la investigación según su relación con la innovación y su utilidad para el desarrollo social, cultural y productivo (Difusión y transferencia)

3) La regionalización del IDT, lo que implica un protagonismo especial de cada comunidad autónoma en su propio desarrollo.

Pero nada de esto es razón suficiente para discriminar financieramente el estudio, la profesión y la docencia. $\mathrm{Y}$ respecto de la docencia conviene recordar que la creación de cuadros de profesorado, en el momento actual y desde hace años, se ha venido vinculando preferentemente a la metáfora de "coste cero".

La relación ciencia, universidad, empresa, sociedad está generando en nuestros días una tensión de demanda que obliga a afrontar las necesidades reales de la institución con la mirada puesta en sus misiones y en el dimensionamiento del conjunto universidadinvestigación-innovación, sin descuidar la formación. Pero nada de ello es incompatible con la defensa y el fomento de la investigación disciplinar desde las carreras universitarias. La investigación es disciplinar, pero la política de IDTi, no, porque empresa gobierno y universidad no tienen los mismos objetivos; hay un salto cualitativo estructural entre ellos, por muy emprendedora que sea la universidad:

- La investigación es disciplinar, aunque sea organizada en redes interdisciplinares, está orientada desde la disciplina científica que genera el enfoque de las preguntas y establece los conceptos y criterios de validación y prueba, pero la política de IDTi no es disciplinar

- Las prioridades de IDTinotienen que coincidir exactamente con las disciplinas científicas o con las tecnologías concretas, ni con un sector de actuación, por muy importante que sea, pero la existencia de instituciones con política propia hacia el desarrollo puede disminuir la importancia y las oportunidades reales de los investigadores, si no trabajan en las líneas decididas en la institución.

- Más financiación, no quiere decir necesariamente más innovación. Puede haber avances de investigación que no son financiados y no necesariamente quien recibe financiación genera innovación, desarrollo tecnológico o nuevas propuestas científicas.

Es importante no olvidar ese salto para mantener abierta siempre la línea de investigación disciplinar en la universidad. Se puede innovar en educación e implementar la oferta innovada. Toda innovación educativa no tiene que ser IDTi; puede ser disciplinar y no responder a objetivos de gobierno y empresariales, sólo a objetivos universitarios de investigación disciplinar. 
Desde mi formación universitaria en Pedagogía, he participado como profesor investigador en actividades de transferencia de conocimiento desde mis primeros años de profesor (ya son 15 trienios). He tenido contrato para implementar la sede universitaria de Barcelona del Centro Ramón Areces y para fijar la estructura de sus guías didácticas. He participado en el grupo CODRA de desarrollo regional en Francia. He tenido contratos con la Administración autonómica para el desarrollo del sistema universitario de la Comunidad autónoma de Murcia. He desarrollado actividades de ordenación universitaria y política científica en situación de servicios especiales en la Xunta de Galicia, relativos al desarrollo del sistema universitario de Galicia, al desarrollo de la ley de fomento de investigación y desarrollo tecnológico, relativos al plan de financiación del sistema universitario y relativos a la red de ciencia y tecnología de Galicia y al CESGA (centro de supercomputación). He realizado actividades culturales por contrato para la Fundación Caixa Galicia y para la Consellería de Cultura. He realizado informes y actividades de gestión del conocimiento y de coordinación de Comunidades por contrato y nombramiento desde la Oficina de Ciencia y Tecnología estatal durante dos años. He creado una red de cooperación al desarrollo que integró a 15 organizaciones de la sociedad civil de América latina. He trabajado en la CNEAI como representante de Comunidad autónoma. He asesorado el programa "Carrera de ciudadanía" para la ciudad de Villavicencio en Colombia. He realizado informes para la USC con contrato de experto para la planificación de la universidad en el horizonte USC 2002. He participado en el máster de la universidad de Salamanca sobre comunicación e información en ciencia y tecnología durante tres años, cuando se defendía que la transferencia de conocimiento era fundamentalmente difusión y propaganda para atraer y fidelizar clientela. He diseñado y creado una revista de cooperación científica bajo relación de trabajo con el IGACI para la difusión del conocimiento científico. He participado con registro de asociado en informes de GAIA (Global Alliance for international advancement, New York) sobre futuro y planificación de la educación. He contribuido a la creación y desarrollo de diversos convenios de colaboración entre universidades. He formado parte de la expedición embajadora a China de la Fundación Eisenhower para la comprensión internacional. He formado parte del grupo nacional de trabajo que elaboró un proyecto para la creación y el desarrollo de la ciudad del conocimiento de Monterrey. He dirigido y creado por medio de proyecto con ATEI una red de difusión por internet de conocimientos de educación en valores y realizado seis foros con sus correspondientes programas de difusión en video streaming. He generado jornadas de puertas abiertas sobre el sistema universitario, jornadas de transferencia de resultados de investigación con Iberoeka, Cyted y Atei, jornadas de transferencia de técnicas de trabajo de ONGs con la Universidad internacional para la paz de la ONU, un congreso mundial con la SID para la cooperación al desarrollo y muy diversos simposios de encuentro, debate y difusión del conocimiento pedagógico. Coordino la red internacional de Pedagogía mesoaxiológica (Ripeme) integrada en Redipe (red iberoamericana de pedagogía), tengo mi propia página web, escribo libros, hago mis investigaciones, formo universitarios $y$ formo $y$ difundo la Pedagogía por Internet y You Tube.

Para todas estas actividades, han venido a buscarme, porque me conocían o tenía relación de amistad profesional, o porque concursé, o porque el boca a boca recomendaba mi trabajo y saber hacer. Mi experiencia es que nunca se ha interesado por mí ningún organismo mediador de transferencia de conocimiento de mi universidad y nunca he recibido ayuda de ellos, ni han publicitado mis trabajos para que empresas del ámbito de educación se pudieran relacionar con mi actividad productiva, ni nunca me anuncié en 
una feria o bolsa de trabajo. Esto que digo, no es una denuncia, sino la constatación empírica de que la transferencia no va del mismo modo, ni por áreas de conocimiento, ni por disciplinas. La experiencia indica que, o bien la transferencia institucional, ni se ocupa de, ni se preocupa por la posibilidad de transferencia de conocimiento individualizada como corresponde y debiera, o bien que los intereses de la transferencia institucional e individual son distintos. La realidad cruda es que los mediadores de la transferencia institucional están muy alejados de los intereses específicos y especializados de la educación.

En mi opinión, no solo hay conocimientos transferibles; hay transferencia como actividad específica y especializada. Yo no soy especialista en transferir y aunque he hecho difusión del conocimiento que he producido $y$ transferencia de conocimiento como he sabido, siempre he sentido la necesidad de que alguien haga de mediador difusor y gestionador del conocimiento que yo he creado. La utilidad de mi trabajo se vería mucho mejor rentabilizada. Las empresas educativas no están próximas a la academia, ni conocen el uso de lo que se hace en la universidad. $\mathrm{Y}$ tampoco saben a dónde acudir, porque los centros en los que estamos trabajando no tienen reconocida su actividad de transferencia y los organismos mediadores se ocupan en otras facetas de la transferencia.

Crear conocimiento, no es transferirlo, y saber crearlo, no es saber transferirlo. Son competencias distintas, con independencia de que haya algunas actividades de transferencia que pueden ser realizadas por un profesor sin especial dominio técnico del proceso de transferencia de conocimiento.

Conocer, enseñar, investigar, gestionar académicamente y representarse a sí mismo y a los demás en la comunidad universitaria, y crear conocimiento son funciones acrisoladas de los profesores de universidad. Incluso cabe admitir que la difusión del conocimiento en revistas, congresos, simposios, prensa escrita y mundo digital son formas de transferencia que van asociadas al conocimiento creado. $Y$ también va asociado al conocimiento su aplicación. Yo siempre destacaré que, cuando fui invitado a participar en el primer número de la nueva época de la Revista Magis (2008, 1:1), una de las exigencias, además de hacer los resúmenes en tres idiomas, era la necesaria cobertura de un apartado estructural en el artículo dedicado a resaltar el valor de transferencia para la práctica del trabajo que se publicaba, tal como puede verse en la página web de la Revista de 2008, https://revistas.javeriana.edu.co/index.php/ MAGIS/issue/view/349 (recuperada el 20 de febrero de 2019).

Pero, cuando hablamos de transferencia, no estamos hablando de aplicación de mi conocimiento, sino de encontrar las vías eficaces de crear una necesidad de esa aplicación o hacer ver esa necesidad a los receptores de la red de transferencia. Eso es algo nuevo que tenemos que aprender a hacer, individualmente, en unos casos, y colectivamente, como facultad, en otros, porque la transferencia no es igual en cualquier área y disciplina. Necesitamos que las facultades tengan competencia y personal especializado en transferencia de conocimiento, con objeto de dar respuesta adecuada a la difusión, aplicación y penetración de nuestro conocimiento creado en los grupos receptores. No estaría de más, en esta misma línea de aproximación de la transferencia de conocimiento a los centros de producción del mismo (facultades, OPIs, investigadores y grupos de investigación), contar en el caso de educación con el ICE (Instituto de ciencias de la educación) para potenciar el valor de servicio ofertable y de desarrollo económico, social, cultural y productivo del conocimiento pedagógico: su función es de asesoría e informes, además de generar investigación como los de los institutos; pero por su peculiar dependencia orgánica de la universidad: la elaboración de informes sobre 
el sistema educativo, la formación y desarrollo de formación pedagógica del profesorado de secundaria (en el futuro, MIR de profesores) y la transferencia de conocimiento relativa a educación encontraría en este organismo una plataforma idónea, distinta y complementaria a la vez, del papel propio de las facultades de ciencias de la educación y de los profesores en esta tarea.

Conviene no olvidar, en concordancia con lo dicho a lo largo de este texto, que el volumen de conocimiento que ya se ha producido en torno a la gestión del conocimiento y su transferencia, permite afirmar que no cabe ninguna duda respecto del carácter especializado y específico de tal tarea.

En el imaginario colectivo de los profesores de universidad, los profesores crean el conocimiento que va a ser transferido por los agentes de la transferencia. $\mathrm{Y}$ el proceso de la transferencia implica, además del conocimiento creado (el objeto a transferir), la obtención del conocimiento especializado y específico del proceso de transferencia que es propio de los mediadores de la transferencia desde las oficinas de transferencia y desde los centros de creación de conocimiento. Eso no impide reconocer, al mismo tiempo, que algunas de las actividades más comunes utilizadas como transferencia son realizadas por los profesores de universidad, por ejemplo: la traducción del conocimiento, la transferencia de conocimientos, el intercambio de conocimientos, las prácticas de ese conocimiento creado, utilización de la investigación, la visualización de sus aplicaciones, la divulgación, la diseminación y la difusión del conocimiento creado. Pero de ahí a convenir que la transferencia es una función más de los profesores de universidad, hay un camino muy largo y un complejo proceso que afecta a intereses, derechos y desarrollo de competencias de los profesores que no se resuelven sin coste, ni sin cambios en la organización de los recursos humanos de la universidad.

La gestión del conocimiento es una tarea profesional que utiliza como instrumento el conocimiento creado por los investigadores. Que sea vista esa tarea como una función más de la profesión de profesor universitario que implica por el momento funciones de docencia, investigación, gestión administrativa y representación institucional, es algo que no se puede establecer sin más. No hay coste cero en esta atribución y tampoco es de recibo desde el punto de vista de la competencia a utilizar que se habilite una forma de evaluar la transferencia de conocimiento y que no se haya habilitado antes un programa de formación de profesores, para el logro de las competencias se requieren para hacer la transferencia. No es lo mismo y es un error grosero de consecuencias injustas para el mérito y la competencia no distinguir entre conocimientos transferibles, creados por los profesores de universidad en el ejercicio de sus funciones profesionales, y transferencia de conocimiento, que es una tarea especializada, distinta de la crear conocimiento.

Necesitamos que la transferencia de conocimiento sea una tarea institucionalmente asumida desde los centros y no solo desde las universidades. La especificidad de la tarea por áreas y por materias nos exige dotar plazas de personal mediador, que dinamice la transferencia y haga el papel técnico. Si estuviéramos en el sistema universitario anglosajón, cada profesor cobraría por cada trabajo de investigación hecho y sería la universidad, institucionalmente la que se responsabilizaría de la transferencia. En nuestro sistema, dado que la mentalidad de evaluación de sexenios ya se ha transferido (en el sentido psicológico del término) a la mentalidad de los profesores, es justo reconocer que hay actividades de cada profesor evaluables como transferencia de conocimiento, atendiendo a la relación de esas actividades con la innovación 
de proceso, de producto y de organización y sin que eso implique renunciar al dinamizador de la transferencia, al transferidor técnico y a la transferencia de la universidad como institución, que, como hemos visto en la introducción, tiene la obligación legal de determinar y establecer los medios e instrumentos necesarios para facilitar la prestación de este servicio social por parte del personal docente e investigador. Un profesor no es un transferidor, pero su trabajo tiene valor de transferencia y hay personal especializado que podría ejercer esa tarea con competencia.

\section{REFERENCIAS BIBLIOGRÁFICAS}

ACUP (2008). Libro Blanco de la Universidad de Cataluña. Barcelona: ACUP (Asociación catalana de universidades públicas).

Alburquerque, F. (2008). Innovación, transferencia de conocimientos $y$ desarrollo económico territorial: una política pendiente. Arbor. Ciencia, Pensamiento y Cultura, 184 (732), 687700 .

Arias, J. E. y Aristizábal, C. A. (2011). Transfrencia del conocimiento orientada a la innovación social en la relación ciencia-tecnología y sociedad. Revista científica Pensamiento y Gestión, 31, 137-166. Recuperado de http:// rcientificas.uninorte.edu.co/index.php/ pensamiento/article/view/3664/4992 (el 15 febrero 2019).

Astigarraga, E. (2019). Universidad, competencias y mundo del trabajo. Recuperado de Universidad sí el 22 de enero de 2019 https://www.universidadsi. es/universidad-competencias-y-mundodel-trabajo/
Barro, S. (2019). La universidad y la empresa aún no se besan. Recuperado el 01/03/2019 de la página https://www.universidadsi. es/la-universidad-y-la-empresa-aun-nose-besan/

Bayona, C. y González, R. (2010). La transferencia del conocimiento en la universidad de navarra. Pamplona: Universidad Pública de Navarra.

Bekkers, R. y Bodas, I. (2008). Analysing Knowledge Transfer Channels between Universities and Industry: to What Degree Do Sectors Also Matter? Research Policy, 37, 1837-1853. Recuperado el 15 de febrero de 2019 de http://www.sciencedirect.com/science/ article/pii/S0048733308001558

Bell, D. (1973). The Coming of Post-Industrial Society: A Venture in Social Forecasting. Nueva York: Basic Books.

Berbegal, J. (2017). Colaboración universidadempresa, sí, pero ¿bajoquécondiciones? Recuperado el 26/09/2017 http:// www.universidadsi.es/colaboracionuniversidad-empresa-condiciones/

Bermejo, J. C. (2018). ¿Cuál es la relación económica entre científicos y el mercado editorial? Recuperado de Universidad sí, el 21 de febrero de 2018 de la página http://www.universidadsi. es/cual-es-la-relacion-economica-realentre-cientificos-y-el-mercado-editorial/

Bozeman, B. (2000). Technology Transfer and Public Policy: A Review of Research and Theory. Research policy, 29: 4, 627-655. Recuperado de http://calitc.pbworks. com/f/TechTransferStudy.pdf 
Broncano, F. (2019). La universidad en funciones. Recuperado el 15/02/2019 de la página https://www. universidadsi.es/la-universidad-en-funciones/

Bueno, E (2007). La tercera misión de la universidad. Boletín Intellectus, 1(12), 9-17.

Bueno, E. (2007). La tercera misión de la universidad: El reto de la Transferencia del conocimiento. Revista madri+d, 41. Recuperado el 25 de enero de 2019 de https://www.madrimasd.org/ revista/revista41/tribuna/tribuna2.asp

Carayannis, E.G. y Campbell, D.F.J. (2012). Mode 3 Knowledge Production 1 in Quadruple Helix Innovation Systems, Twenty-first-Century Democracy, Innovation, and Entrepreneurship for Development. SpringerBriefs in Business, 7, https://www.springer.com/la/book/9781461420613 recuperado el 22 de febrero de 2019.

Carayannis, Elias G, David F. J. Campbell (2010). Triple Helix, Quadruple Helix and Quintuple Helix and How Do Knowledge, Innovation and the Environment Relate To Each Other? A Proposed Framework for a Trans-disciplinary Analysis of Sustainable Development and Social Ecology. International Journal of Social Ecology and Sustainable Development, 1 (1), 41-69. Recuperado el 16 de enero de 2019 de http://www.igi-global.com/bookstore/article.aspx?titleid=41959

Carayannis, Elias G., David F. J. Campbell (2009). "Mode 3" and "Quadruple Helix": Toward a 21st Century Fractal Innovation Ecosystem. International Journal of Technology Management, 46 (3/4), 201-234. Recuperado el 16 de enero de 2019 https://www.inderscience.com/infol inarticletoc. . php?jcode $=$ ijtm $\&$ year $=2009 \&$ vol $=46 \& i s s u e=3 / 4$

Castro, E.; Fernández, I.; Pérez, M. y Criado, F. (2008). La transferencia de conocimiento desde las humanidades: posibilidades y características. Arbor. Ciencia, Pensamiento y Cultura, 184 (732), 619-632.

Clark, B. (1998). Creating Entrepreneurial Universities: Organisational Pathways of Transformation. Nueva York: International Association of Universities and Elsevier Science.

Claxton, G. (2001). Aprender. El reto del aprendizaje continuo. Buenos Aires: Paidós.

Comisión de las Comunidades Europeas (1995). Einseigner et appendre. Vers la societé cognitive. Bruselas, 29.11.1995. COM(95) 590 final. http://eur-lex.europa.eu/LexUriServ/LexUriServ. do?uri=COM:1995:0590:FIN:ES:PDF Recuperado el 23 de febrero de 2013.

Comisión de las Comunidades Europeas. (1995). Libro Verde de la Innovación. Bruselas: ES/13/95/55220800.P00 (FR) aq/rc.

Comisión de las Comunidades Europeas. (2004). Innovation Management and the Knowledge-Driven Economy. Brussels-Luxembourg: ECSC-EC-EAEC.

Comisión de las Comunidades Europeas. (2004): The Europe of Knowledge 2020: A vision for University-Based Research and Innovation, Liege. https://www.forskningsradet.no/csstorage/ flex_attachment/LiegeKonferanse0404.pdf Recuperado el 28 de enero de 2019.

Comisión de las Comunidades Europeas. (2005). El triángulo de la sociedad del conocimiento en 
Europa. Bruselas: Comunicación, 6 de abril de 2005.

Comisión de las Comunidades Europeas. (2011). Libro Verde. Del reto a la oportunidad: hacia un marco estratégico común para la financiación de la investigación y la innovación por la UE. Bruselas, 9.2.2011 $\operatorname{COM}(2011) 48$ final.

Conesa, F. (2019). Transferencia versus transmisión de conocimiento: los nuevos sexenios. https://www.universidadsi. es/transferencia-versus-transmisionde-conocimiento-los-nuevos-sexenios/ (Recuperado el 7 de marzo de 2019).

CRUE (2018). Transferencia de conocimiento. Nuevo modelo para su prestigio e implulso. Madrid: CRUE-Santander universidades. (Coordinador del grupo de trabajo, Salustiano Mato).

Drucker, P (1993). Post-Capitalist Society. Oxford: Butterworth-Heinemann.

Drucker, P. (1969). The Age of Discontinuity. Nueva York: Harper and Row.

Etzkowitz, H. y L. Leydesdorff (1995): The Triple Helix-University-Industry-Government Relations: A Laboratory for KnowledgeBased Economic Development, EASST Review, 14 (1), 14-19. Recuperado el 25 de enero de 2019 de https://papers. ssrn.com/sol3/papers.cfm?abstract id $=2480085$

Faure, E. (1973). Aprender a ser. Madrid: Alianza. (Primera edición UNESCO, 1972).

Fernández, A. (2000). Organización y gestión de empresas. ACoruña: UDC (Universidade da Coruña).

FH JOANNEUM (2010). Intellectual Capital Report 2009/2010. Annual Report
2009/2010. A Journey Through the World of Education and Research at $\mathrm{FH}$ JOANNEUM. Austria: FH JOANNEUM. University of Applied Sciences, p. 51. https://issuu.com/fhjoanneum/docs/ gbwb0910_e/47 (Recuperado el 15 de enero de 2019).

Fraser, A. G. y Dunstan, F. D. (2010). On the Impossibility of Being Expert. BMJ 2010;341:c6815. https://www.bmj.com/ content/341/bmj.c6815.full

Frida Díaz-Barriga, F. (2010). Los profesores ante las innovaciones curriculares Revista Iberoamericana de Educación Superior RIES, 1(1), 2010, 37-57. http://www.scielo.org.mx/pdf/ries/v1n1/ v1n1a4.pdf

Gagné, R.M. (1971). Las condiciones del aprendizaje. Madrid: Aguilar.

García, D. (2019). La conexión universidadempresa, vista desde la empresa. https:// www.universidadsi.es/la-conexionuniversidad-empresa-vista-desde-laempresa/ Recuperado de Universidad sí, el 24 de enero de 2019.

Gibb, A.A. (1993): The enterprise culture and education: understanding enterpris education and its links with small business, entrepreneurship and wider educational goals. International Small Business Journal, 11 (3), 14-34.

Gibbons, M. (1998). Higher Education Relevance in the 21st Century. Paris: UNESCO World Conference on Higher Education.

Gibbons, M.; Limoges, C.; Nowotny, H.; Schwartzman, S.; Scott, P. y Trow, M. (1994): The New Production of Knowledge. Londres: Sage.

Gibbons, M; Limoges, C; Nowotny, H; 
Schwartzman, S; Scott, P. y Trow, M. (1994). The New Production of Knowledge-The Contemporary Societies. Londres: SAGE.

Gómez Sal, J. C. (2016). La función de transferencia en las universidades: algunas ideas sobre indicadores clave y su aplicabilidad. http:// www.universidadsi.es/la-funciontransferencia-las-universidadesalgunas-ideas-indicadores-claveaplicabilidad-i/ Recuperado de Universidad sí, el 4 de enero de 2019.

Gómez, C. B.; Sanjosé V. y Solaz-Portolés J. J. (2012). Una revisión de los procesos de transferencia para el aprendizaje y enseñanza de las ciencias. Didáctica de las Ciencias Experimentales y Sociales, 26, 199-227.

González, T. de la (2009). El modelo de Triple Hélice de relaciones universidad, industria y gobierno: un análisis crítico. Arbor. Ciencia, Pensamiento y Cultura, 185 (738) 739-755. http://arbor.revistas. csic.es/index.php/arbor/article/view/327 Recuperado el 14 de febrero de 2019.

Graham, I. D.; Logan, J.; Harrison, M.; Straus, S.; Tetroe, J.; Caswell, W. y Robinson, N. (2006). Lost in Knowledge Translation: Time for a Map? The Journal of Continuing Education in the Health Professions, 26, 13-24.

Haskell, R. E. (2001). Transfer of Learning: Cognition, Instruction and Reasoning. San Diego, CA: Academic Press.

Haug, G. y otros (2018). Universidades y empresas. Apuntes para crear sinergias con sentido. Madrid: Studia $X X 1$. Fundación Española Sociedad y Educación.
Herbart, J. F. (1806). Pedagogía General derivada del fin de la educación. Madrid: La lectura, s. f.

Herrera, E.; Bonilla, H. y Molina, L. F. (2013). Ciudades creativas: ¿paradigma económico para el diseño y la planeación urbana? Revista Bitácora Urbano Territorial, 22 (1), 11-20.

Hidalgo, A.; León, G. y Pavón, J. (2002). La gestión de la innovación y la tecnología en las organizaciones. Madrid: Ediciones Pirámide.

Husén, T. (1978). La sociedad educativa. Madrid: Anaya.

Hutchins, R. (1968). The Learning Society. Londres: Penguin.

López, O.; Blanco, M. y Guerra, S. (2009). Evolución de los modelos de la gestión de innovación. Innovaciones de Negocios, 5 (2), 251-264.

López-Varela, A. (2018). El papel de las asociaciones como redes intersectoriales: Marie Curie Alumni Association (MCAA). Recuperado el 16/03/2018 de http://www.universidadsi. es/el-papel-de-las-asociaciones-comoredes-intersectoriales-marie-curiealumni-association-mcaa/

Luque, R. (2016). ¿Fin de la iniciativa de Campus de Excelencia Internacional (CEI)? http:// www.universidadsi.es/fin-la-iniciativacampus-excelencia-internacional-cei/ Recuperado 04/11/2016.

Luque, T. (2018). Universidad "Blockchain". Recuperado de Universidad sí, el 24 de julio de 2018 http://www.universidadsi. es/universidad-blockchain/

Martín, C. y otros (1986). Investigación, innovación y tecnología. Barcelona: 
Orbis, Biblioteca de Economía Española.

Martínez, A. (2008). Modelos de innovación: un análisis integral. Primer Seminario Nacional de Economía Institucional. Recuperado el 15 de enero de 2019 de la página https://www.researchgate.net/ publication/313427240

Martínez-Gómez, J. (2017). Procesos de transferencia del conocimiento en una Facultad de Ciencias Contables. Revista Espacios, 38 (50), 1-7. https:// www.revistaespacios.com/a17v38n50/ a17v38n50p01.pdf Recuperado el 17 de enero de 2019.

Medina, A. (2016). Aportes multidisciplinarios para la innovación científica y transferencia tecnológica. AnnArbor (Michigan)-Cali (Colombia): ProQuest (Bowker Books In Print)-RedipeTecnológico Superior de Jalisco.

Messadié, G. (1999). Grandes descubrimientos de la ciencia. Madrid: Alianza Editorial.

Messadié, G. (2000a). Grandes inventos de la humanidad (hasta 1850). Madrid: Alianza Editorial.

Messadié, G. (2000b). Grandes inventos del mundo moderno (desde 1850). Madrid: Alianza Editorial.

Molero, J. (2008). La transferencia de tecnología revisada: conceptos básicos y nuevas reflexiones a partir de un modelo de excelencia de gestión. Arbor. Ciencia, Pensamiento y Cultura, 184 (732), 637651.

Nieto, J. (2008). Y tú, ¿innovas o abdicas? Valencia: Universidad Politécnica de Valencia.

Nowotny, H; Scott, P. y Gibbons, M. (2001). Re-thinking Science, Knowledge and the Public in An Age of Uncertainty, Cambridge, Oxford: Polity Press.

OMS (2007). Ciudades globales amigables con los mayores: una guía. Ginebra: Organización Mundial de la Salud.

Ortega, P.; Ramírez, Mª. E.; Torres, J. L.; López, A. E.; Servin, C. Y.; Suárez, L. y Ruiz, B. (2007). Modelo de innovación educativa. Un marco para la formación y el desarrollo de una cultura de la innovación. RIED,10 (1), 145-173. http:// www.biblioteca.org.ar/libros/142346.pdf Recuperado el 21 de enero de 2019.

Padmore, T., Schuetze, H. y Gibson, H. (1998). Modeling Systems of Innovation: An Enterprise-Centered View. Research Policy, 26, 605-624.

Pirnay, F., Surlemont, B. y Nlemvo, F. (2003): Toward a Typology of University Spinoff. Small Business Economics, 21 (4), 355-365.

Ramos, $M^{a}$. (2019). La formación en Empresas y Universidades, también a lo largo de la vida. Recuperado de Universidad sí, el 4 de enero de 2019 de la página https:// www.universidadsi.es/la-formacion-enempresas-y-universidades-tambien-alo-largo-de-la-vida/

Rodríguez, P. (2017). La misión social de la universidad, más allá de la transferencia del conocimiento Recuperado el 22/06/2017 de la página http://www. universidadsi.es/la-mision-social-launiversidad-mas-alla-la-transferenciadel-conocimiento/

Rosli, A. y Rossi, F. (2014). Monitoring the Knowledge Transfer Performance of Universities: An International Comparison of Models and Indicators. CIMR Research Working Paper. Working 
Paper No. 24. Series Universidad de Londres. http://www.bbk.ac.uk/ innovation/publications/docs/WP24.pdf Recuperado el 15 fde febrero de 2019-

Salaburu, P. (2017). Universidad y empresa. ¿Dos mundos? Recuperado el 05/10/2017 de la pagina http://www. universidadsi.es/universidad-empresados-mundos/

Scheffler, I. (1970). El lenguaje de la educación. Buenos Aires: El Ateneo.

Sebastián, J. (2008). La transferencia de conocimientos en la cooperación al desarrollo. Arbor. Ciencia, Pensamiento y Cultura, 184 (732), 719-728.

SI(e)TE (2012). Creatividad, educación e innovación: emprender la tarea de ser autor y no sólo actor de sus propios proyectos. Revista de Investigación en Educación, 10 (1), 7-29.

SID (1997). ¿Qué globalización? Actas del Congreso mundial de la Sociedad Internacional para el Desarrollo. Santiago de Compostela: Xunta de Galicia.

SID (2000). Globalization and Knowledge Society: Expert Meeting. Santiago de Compostela: IGACI.

Slaughter, S. y L. Leslie (1997): Academic Capitalism: Politics, Policies and the Entrepreneurial University. Baltimore: John Hopkins University Press.

Telford, R. (1990). Escuela e industria. Dictamen IRDAC (Industrial Research and Development Advisory Commission). Grupo XI. Comisión de las Comunidades Europeas. Bruselas.

Touriñán, J. M. (2000). Globalización y desarrollo: un reto de las políticas regionales de
IDT. Santiago de Compostela: Centro de Investigación Económica y financiera (CIEF). Colección monografías. Serie: Documentos de Economía.

Touriñán, J. M. (2008). Decisión política y politización de la decisión: complejidad estructural de la decisión en política educativa, en J. Evans, y E. Kristensen, (Eds.), Investigación, desenvolvemento e innovación. Santiago: USC, pp. 11-50.

Touriñán, J. M. (2014). Dónde está la educación. Actividad común interna y elementos estructurales de la intervención. A Coruña: Netbiblo (Disponible en PDF en mi página web http:// dondestalaeducacion.com ).

Touriñán, J.M.(2015). Pedagogíamesoaxiológica y concepto de educación. Santiago de Compostela: Andavira (Disponible la $2^{\text {a }}$ edición de 2016).

Touriñán, J. M. (2016). Pedagogía general. Principios de educación y principios de intervención. A Coruña: Bello y Martínez.

Touriñán, J. M. (2017). Mentalidad pedagógica y diseño educativo. De la pedagogía general a las pedagogías aplicadas en la función de educar. Santiago de Compostela: Andavira.

Touriñán, J. M. (2018). Concepto de educación y conocimiento de la educación. The Concept of Education and the Knowledge of Education. AnnArbor (Michigan)-Cali (Colombia): ProQuest (Bowker Books In Print)-Redipe.

Touriñán, J. M. y Bravo, A. (Eds.) (2000). Gestión de política científica y recursos de investigación. Santiago de Compostela: Instituto Galego de Cooperación Iberoamericana. 
Trott, P. (2002). Innovation Management and New Product Development. Essex, UK: Prentice Hall, 2nd ed.

UNESCO (1997). Nuestra diversidad creativa. Informe de la Comisión mundial de Cultura y Desarrollo. Madrid: UNESCOSM. Fundación Santa María.

UNESCO (2005). Hacia las sociedades del conocimiento. París: UNESCO. http://unesdoc.unesco.org/ images/0014/001419/141908s.pdf

UNESCO. (2008). Hacia unos indicadores de alfabetización informacional. Paris: División de la Sociedad de la Información.

Upstill, G. y Symington, D. (2002). Technology Transfer and the Creation of Companies: the CSIRO Experience. $R \& D$ Management, 32 (3), 233-239.

Velasco, E.; Zamanillo, I. y Intxaurburu, G. (2007). Evolución de los modelos sobre el proceso de innovación: desde el Modelo lineal hasta los Sistemas de innovación. XX Congreso anual de AEDEM. 2. Palma de Mallorca: Asociación Europea de Dirección y Economía de Empresa. Recuperado el 21 de enero de 2019 de https://www. researchgate.net/publication/28200735

Vidal, J. (2018) ¿Qué es esto de la tercera misión? Recuperado el 19/01/2018 de la página http://www.universidadsi.es/latercera-mision/

Vilalta, J. (2013). La tercera misión universitaria. Innovación y transferencia de conocimientos en las universidades españolas. Madrid: Studia XX1. Fundación Española Sociedad y Educación.
Vilalta, J. M. (2016). Conectando formación, investigación e innovación. Recuperado el 30/06/2016 de la página http://www. universidadsi.es/conectando-formacioninvestigacion-e-innovacion/

Vilalta, J. P. (2018) Un elemento para la innovación: la inserción de los doctores en el tejido económico. Recuperado el 24/07/2018 de la página https:// www.universidadsi.es/un-elementopara-la-innovacion-la-insercion-de-losdoctores-en-el-tejido-economico/

Ziman, J. (1994). Prometeus Bound: Science in a Dynamic Steady State. Cambridge (U.K.): Cambridge University Press. 